\title{
AJRC
}

\author{
Australia - Japan Research Centre
}

\section{Policy Regime Change against Chronic Deflation? Policy option under long-term liquidity trap*}

\section{AJRC Working Paper 02/2014 April 2014}

\section{Ippei Fujiwara}

RIETI/Keio University/Australian National University

Yoshiyuki Nakazono

Yokohama City University

\section{Kozo Ueda}

Waseda University

\begin{abstract}
The policy package known as Abenomics appears to have influenced the Japanese economy drastically, in particular, in the financial markets. In this paper, focusing on the aggressive monetary easing of Abenomics, the first arrow, we evaluate its role in guiding public perceptions on monetary policy stance through the management of expectations. In order to end chronic deflation, such as that which Japan has been suffering over the last two decades, policy regime change must be perceived by economic agents. Analysis using the QUICK survey system (QSS) monthlysurvey data shows that monetary policy reaction to inflation rates has been in a declining trend since the mid 2000s, implying intensified forward guidance well before Abenomics. However, Japan seems to have moved closer to a long-term liquidity trap, where even long-term bond yields are constrained by the zero lower bound. Consequently, no sizable difference in perceptions has been found before and after the introduction of Abenomics. Estimated changes in perceptions are not abrupt enough to satisfy "Sargent's (1982) criteria for regime change" termed by Eggertsson (2008). This poses a serious challenge to central banks: what is an effective policy option left under the long-term liquidity trap?
\end{abstract}


*We thank the discussant, Kosuke Aoki, for invaluable inputs and have also benefited from discussions with Shin-ichi Fukuda, Etruso Shioji, Masahisa Fujita, Hideo Hayakawa, Yasuo Hirose, Takuji Kawamoto, Jinill Kim, Takushi Kurozumi, Colin McKenzie, Tsuyoshi Mihira, Tsutomu Miyagawa, Ryuzo Miyao, Masayuki Morikawa, Atsushi Nakajima, Jochi Nakajima, Koji Nakamura, Masao Ogaki, Yoshikiyo Sakai, Masaya Sakuragawa, Toshitaka Sekine, Mototsugu Shintani, Hajime Tomura, Kazuo Ueda, Masazumi Wakatabe, Tomoaki Yamada, Yohei Yamamoto, Tomoo Yoshida, and participants in the TCER-CIRJE-JJIE conference on "Abenomics" and seminars at the Bank of Japan, Daiwa Institute of Research, Gakushuin University, JSRI, Kanagawa University, Keio University, RIETI, Waseda University and Yokohama City University. The authors also thank the QUICK corporation for permission to use panel data on each individual forecast. This research was conducted while Fujiwara was a visiting scholar at RIETI. Fujiwara thanks RIETI for their support and hospitality during this time.

\section{Keywords}

Monetary policy rule; Liquidity trap; Survey forecasts

\section{JEL Classification}

E47; E50; E60

\section{Suggested Citation:}

Fujiwara, I., Nakazono, Y. \& Ueda, K. 2014. Policy Regime Change against Chronic Deflation? Policy option under long-term liquidity trap, AJRC Working Paper No.2/2014, April. Australia-Japan Research Centre, Crawford School of Public Policy, The Australian National University.

\section{Address for correspondence:}

(E) ajrc@anu.edu.au

ISSN 07288409

ISBN 978-0-86413-001-3

The Australia-Japan Research Centre (AJRC) conducts research to explore and improve understanding of the economies and economic policy processes in Australia and Japan and both countries' strategic interests in the Asia Pacific economy.

The AJRC Working Paper Series aims to provide a forum for the exchange of topical research and contains the latest research and analysis on the Japanese economy, as well as the political economy, regional integration and trade. The views expressed in AJRC Working Papers are those of the individual authors and do not represent the views of the Australia-Japan Research Centre, the Crawford School, or the institutions to which authors are attached.

The Crawford School of Public Policy is the Australian National University's public policy school, serving and influencing Australia, Asia and the Pacific through advanced policy research, graduate and executive education, and policy impact. 


\section{Introduction}

Over the last two decades, Japan has suffered chronic deflation. Some compare this situation to the prolonged deflation of the Great Depression in the 1920s and 1930s, or, conversely, to the Great Inflation in the 1970s. To date, as shown by Sargent (1982), Temin and Wigmore (1990), and Eggertsson (2008), one conventional wisdom in academic literature to tackle chronic inflation or deflation is to induce policy regime change through the management of expectation a la Woodford (2003). In this paper, we examine whether the Bank of Japan, in particular, from the end of 2012, induced such a policy regime change.

After returning to the position of the Governor of Liberal Democratic Party in September 2012 and Prime Minister in December 2012, Mr. Abe introduced the package of policies known as Abenomics, consisting of three arrows: aggressive monetary easing; flexible fiscal spending; and a growth strategy. This policy package appeared to have drastically influenced macroeconomic and, in particular, financial variables to date. The exchange rate depreciated considerably from 82 yen to the dollar at the end of November 2012 to 97 yen to the dollar at the end of April 2013. The stock price of the Nikkei 225 increased massively from 9,446 yen at the end of November 2012 to 13,860 yen at the end of April 2013.

Many argue that, among the three, the first arrow should have played a significant role in these developments, albeit casually. During this period, the target level of inflation was raised from 1 to $2 \%$ in January 22, 2013. Also, Mr. Kuroda, newly appointed Governor of the Bank of Japan in March, also introduced the Quantitative and Qualitative Monetary Easing ( $Q Q M E)$ policy on April 4, 2013, by stating "[i]t will double the monetary base and the amounts outstanding of Japanese government bonds (JGBs) as well as exchangetraded funds (ETFs) in two years, and more than double the average remaining maturity of JGB purchases." 1

Even though the QQME is massive and outstanding in terms of the increase in amount

\footnotetext{
${ }^{1}$ Newly-introduced policy tools include (1) the adoption of the "monetary base control"; (2) an increase in JGB purchases and their maturity extension; (3) an increase in ETF and J-REIT purchases; and (4) the continuation of the QQME.
} 
of the base money, it is well-known that quantitative easing and therefore the QQME per se do not have a large impact on the macroeconomy. Eggertsson and Woodford (2003) propose the "irrelevance proposition for open-market operations" under the zero lower bound. This is because, in the standard new Keynesian model, (the quantity of) money is irrelevant to equilibrium determination. ${ }^{2}$ Sargent (1981) argues "it was not simply the increasing quantity of central bank notes that caused the hyperinflation" in Germany, Austria, Hungary, and Poland.

What comes to matter even under the zero lower bound is the forward guidance policy, which has been adopted by the Bank of Japan as well as other central banks. As recommended by Jung, Teranishi and Watanabe (2005) and Eggertsson and Woodford (2003), thus far, the commitment policy for future monetary easing is believed to be the most effective tool for monetary policy under a liquidity trap. In terms of policy regime change, Eggertsson (2008) states "a higher money supply increases demand only through lower interest rates, so at the zero lower bound it is only through the expectation of future money supply, and thus future interest rates, that the money supply affects spending" or "this could be achieved only through the correct management of expectations, not contemporaneous increases in the money supply per se." Woodford (2012) further argues that " $[\mathrm{m}]$ uch of the effect of balance-sheet policies seems to have resulted from their being taken as a signal about likely future policy." Bhattarai, Eggertsson, and Gafarovy (2014) term this as a "signalling role of quantitative easing," and conclude that "[i]n fact, arguably, much of the findings of the empirical literature on reduction of long-term

\footnotetext{
${ }^{2} \mathrm{~A}$ notable exception is nonseparability between the consumption and real balance in utility as analyzed in Koenig (1990). Fujiwara (2007) shows the degree of nonseparability is small.

Furthermore, the "portfolio balance" effect coined by Tobin (1958), as studied in Orphanides and Wieland (2000) in the context of foreign exchange rates and Gagnon, Raskin, Remache and Sack (2011) and Joyce, Lasaosa, Stevens and Tong (2011) in terms of long-term bond yields, may work. Empirical investigation of the portfolio balancing channel is, however, difficult, as it involves expected covariances among returns in financial variables.

Note also that as Cochrane (2011) argues, helicopter money, namely printing money and giving it to economic agents directly, is "at heart a fiscal operation. It is a transfer payment." There, a "central bank may be almost powerless to avoid deflation or inflation." Such a policy has not been examined yet in any country as a method to fight deflation.
} 
interest rates due to quantitative easing can be attributed to expectations of low future short-term interest rates." ${ }^{3}$ In this vein, an increase in base money as examined by the QQME may imply strong commitment in terms of policy duration and possibly, at the same time, further monetary easing in the future.

Indeed, the minutes of the Monetary Policy Meeting more than a decade ago, of March 19, 2001, report that "[o]ne member proposed that in the current environment where reducing interest rates would have only a limited effect on the economy, the Bank should consider increasing the amount of government bonds it bought outright, in order to affect the public's expectations and underline the Bank's commitment to the targeted interest rate in terms of duration."

So, the success of new measures in monetary policy after Abenomics hinges on whether it can induce an abrupt change, a regime shift, or an upheaval in agents' perceptions of monetary policy stance toward a stronger forward guidance. Kuroda (2013a) indeed states that the QQME is intended "to drastically change the expectations of markets and economic entities." Sargent (1982) argues that "[t]here must be an abrupt change in the continuing government policy, or strategy, for setting deficits now and in the future that is sufficiently binding to be believed." Eggertsson (2008) calls this "Sargent's (1982) criteria for regime change." As analyzed in Eggertsson (2008), regime shift must be observed as changes between policy rules. ${ }^{4}$

A regime change is also called for, in order to exit from deflationary expectation as in Benhabib, Schmitt-Grohe, and Uribe (2002). ${ }^{5}$ Inflation expectation may have been

\footnotetext{
${ }^{3}$ See, for example, Krishnamurthy and Vissing-Jorgensen (2011), or Bauer and Rudebusch (2013).

${ }^{4}$ In Eggertsson (2008), the difference between the Hoover and the Roosevelt regimes is found in the welfare maximization problem by the social planner. The latter is not subject to the fiscal dogma. Thus, the solutions, namely the optimal policy rules, are inevitably different between these two regimes.

${ }^{5}$ Another possible criterion for a regime change is the Taylor principle. Clarida, Gali, and Gertler (2000) and Lubik and Schorfheide (2004) point out (in)determinacy as the key to separating economic policy performance around the late 1980s and the early 1980s. They argue that the Federal Reserve under Chairman Volker changed from passive to active monetary policy, which made equilibrium determinate. Unlike during that period, in Japan the zero lower bound is constraining current monetary policy. In such a case, shifting from determinacy to indeterminacy may have some virtue. This shift generates self-fulfilling expectations, which may help the escape from deflationary expectation as in Benhabib, Schmitt-Grohe, and Uribe (2002). For this reason, it is important to check if the Taylor principle is
} 
stuck below zero for a long time. Figure 1 illustrates that if monetary policy follows a Taylor type of rule, multiple equilibria emerge with two steady states as the crossing points between the policy rule and the Fisher equation. The so-called deflationary steady state emerges, even if commitment to a positive target level of inflation is fully credible. Once the economy gets stuck there, a superinertial monetary policy rule or the price level targeting can eliminate the deflationary trap, as investigated by Sugo and Ueda (2008b). Thus, if the deflation continues as a result of the economy being stuck at the deflationary steady state, policy regime shift is the only theoretical way to exit from deflationary expectation.

Modern macroeconomics emphasizes the importance of the management of expectation in public policy. Expectation is, however, not the control variable but a mere consequence of policy actions. ${ }^{6}$ Even when a public authority initiates an abrupt policy change, a clear and stable structural relationship between controllable tools implemented by public policy and expectation must exist for the policy to be effective. If such a relationship does not exist, policy cannot be credible and expectation may become uncontrollable.

In this paper, we empirically evaluate changes in monetary policy stance to examine if there has been a monetary policy regime shift in Japan. ${ }^{7}$ In order to determine whether

satisfied in the case of Japan's monetary policy, but this lies beyond the scope of this paper. Obtaining a precise estimate of monetary policy stance is difficult due to endogeneity and the zero lower bound. Therefore, examining if there is any monetary policy regime change is the sole aim of this paper.

${ }^{6}$ Hausman and Wieland (2014) give an overview of economic and financial developments before and after Abenomics. They, however, admit that they lack the theoretical explanation of the management of expectation, writing "[a]n important caveat is that we treat Abenomics as is. That is, we take as given the effect of Abe's policies on expected inflation and expected future output."

Romer (2013) claims that "[t]he regime shift we are seeing in Japan is just the kind of bold action that might actually succeed in changing both inflation and growth expectations a substantial amount. As a result, it may be an effective tool for encouraging robust recovery and an end to deflation." Yet, the theoretical channel as to which the regime shift is brought about is not explained. Indeed, it is written that "[m]y support for that conclusion is based less on theory and more on economic history."

${ }^{7}$ Empirical attempts to evaluate changes in monetary policy stance under the zero lower bound include Fujiki and Shiratsuka (2002), Kamada and Sugo (2006), and Nakazono and Ueda (2013). Fujiki and Shiratsuka (2002) investigate daily changes in bond yields. Kamada and Sugo (2006) identify 
there has been a monetary policy regime shift, we look at individuals' expectation formations using survey data called the QSS (QUICK survey system), provided by the QUICK corporation. The QSS asks each market participant about the future courses of interest rates as well as inflation rates. Such data enable us to identify changes in monetary policy stance or monetary policy reaction functions perceived by market participants, through the evaluation of interest-rate expectations over inflation expectations.

The QSS can resolve or alleviate the following two empirical challenges. First, obtaining the precise estimate of monetary policy stance is difficult due to the zero lower bound constraint. Second, data are usually not long enough in a time-series dimension to have a reliable real-time estimate of a monetary policy rule. Only one year has passed since the policies of Abenomics began; 12 samples monthly or 4 samples quarterly are too short to evaluate monetary policy stance effectively. By following the spirits in Kim and Pruitt (2013), the use of long-run forecasts in the QSS alleviates the first problem. Even though the long-term bond yields are very low, they are positive and show some dynamics depending on macroeconomic environments. We can still observe the time-variations in the monetary policy stance perceived by the market participants. ${ }^{8}$ Regarding the second problem, the novelty of the QSS is to have the panel data of expectations, increasing the degrees of freedom toward cross-sectional dimension. This allows us to examine whether regime change in monetary policy is perceived by market participants or not, even with short time-series data.

The analysis using the QSS shows, first, that an increase in inflation expectations is small at the onset of Abenomics. Inflation expectations rose only gradually and modestly. No significant increase in long-term inflation expectations is observed, when it is evaluated by median. The median inflation expectations remain at $1 \%$. The increase in inflation expectations in mean is mainly driven by the upper tail of the distribution. Therefore, in terms of perceptions regarding long-term inflation, Abenomics brought about no abrupt impact. Second, monetary policy reaction, captured by the coefficient

monetary policy shocks by imposing sign restrictions. Nakazono and Ueda (2013) use the same QSS, but their focus is on the period of the previous quantitative easing policy until 2006.

${ }^{8}$ Kim and Pruitt (2013) sidestep the censoring problem by using one-year-ahead forecasts of the short rate, which stayed above zero at least until August 2011. 
of the interest rate on the inflation rate, became continuously smaller between 2004 and 2013. This suggests that the Bank of Japan has been intensifying the forward guidance throughout this sample, well before the introduction of Abenomics. The perceived monetary policy stance turns out to be close to superinertial or price-level targeting. ${ }^{9}$ Third, no significant difference in monetary policy reaction, or no regime shift in monetary policy, is perceived before and after the introduction of Abenomics. The above coefficient reached zero, before the introduction of Abenomics. Very little room existed for further monetary policy accommodation. That is, the Japanese economy is considered to be close to a long-term liquidity trap, where not only short-term but also long-term bond yields are constrained by the zero lower bound. Consequently, we cannot find any significant evidence that the first arrow of Abenomics, in particular, the QQME has abruptly changed perceptions on how monetary policy will be conducted in the future. In summary, the QSS data on inflation and interest-rate expectations reveal no significant regime shift in monetary policy after the introduction of Abenomics or the QQME. Under the long-term liquidity trap, the forward guidance policy hinders its effectiveness. How could then a central bank design effective policy tools to exit from such a trap?

The structure of this paper proceeds as follows. Section 2 illustrates how macroeconomic variables responded to Abenomics. Section 3 first discusses the details of the QSS data and then investigates changes in perceptions about the monetary policy stance. Section 4 summarizes findings in this paper and concludes.

\section{Abenomics and Macroeconomy}

Figure 2 plots time-series developments in annual growth rates in GDP, annual inflation rates of the consumer price index $(\mathrm{CPI})$, real effective exchange rates, yields on 10-year JGBs, and the Tokyo stock price index (TOPIX), from January 2011. The volatility index (VIX) of S\&P500 is also shown as the proxy for the conditions of international

\footnotetext{
${ }^{9}$ This result implies that expectation trap as examined in Albanesi, Chari and Christiano (2003) may not hold in Japan. Again, even if the economy is subject to the expectation trap where discretionary monetary policy results in the Markov Perfect equilibrium, such a situation is overturned only by the policy regime change.
} 
financial markets. The shaded area is drawn from November 2012 when Abenomics started. ${ }^{10}$ Significant changes are observed in the dynamics of some financial variables at the end of 2012. The Japanese yen has depreciated (real effective exchange rates dropped) massively and the TOPIX rose significantly. Albeit less dramatic and more sluggish, real economic variables, such as GDP and inflation rates, also increased.

These developments in financial as well as real economic variables seem to suggest the success of Abenomics. Such a casual evaluation, however, needs some reservations. Reflecting on the consecutive trade surpluses, Japan has the largest net foreign assets. Thus, the Japanese yen is said to be a safe haven currency. As a result, yen tends to appreciate when international financial markets are at risk-off, or when the VIX is high. Against this background, currency depreciation from the middle of 2012 may be related to conditions in global financial markets. Indeed, currency depreciation from the end of 2012 coincides with the period when the VIX stabilized.

A key variable to evaluating the effectiveness of the first arrow is long-term bond yields. Under the liquidity trap, a central bank cannot lower short-term nominal interest rates. Thus, economic variables must be influenced through the commitment on the future course of policy interest rates, that is, forward guidance. Such a commitment policy must be reflected in changes in long-term bond yields. Overall, long-term bond yields declined after the introduction of Abenomics. The dynamics, however, were volatile. In particular, long-term bond yields jumped up in May 2013, just after the introduction of the QQME. The market reacted in an opposite direction to the intention of the Bank of Japan. The QQME is a policy "[w]ith a view to encouraging a further decline in interest rates across the yield curve" by purchasing a vast amount of long-term government bonds. The increase in bond yields is also clearly inconsistent with the intended consequences of this unconventional monetary policy as examined in Gagnon, Raskin, Remache and Sack (2011) or Joyce, Lasaosa, Stevens and Tong (2011).

\footnotetext{
${ }^{10} \mathrm{Mr}$. Abe became prime minister in December 2012. We, however, chose November 2012 as the month when Abenomics was introduced. Our reason for this is that his election victory was widely predicted when the lower house was dissolved in November 2012.
} 


\section{QSS}

This paper exploits the QSS (QUICK survey system) data provided by the QUICK corporation. The QSS is a survey of forecasts on financial as well as macro economic variables. The QUICK corporation asks market participants monthly about their forecasts on bond markets and inflation developments. Respondents include market participants from securities firms, banks, investment trusts, insurance firms, pension funds, and other private financial institutions. They are mostly experts in bond markets and work in Japan. The QSS is an unbalanced panel with about 150 respondents per month.

The novelty of the QSS is to have the panel data of expectations for both inflation rates and bond yields for each respondent. This allows us to examine whether regime change in monetary policy is perceived by market participants or not, even though there is not enough time-series data. Respondents submit their answers at the end of each month. Interest rates are those of newly issued government bonds at the maturity of 2, 5, 10, and 20 years. For each, 1-, 3-, and 6-month ahead expectations are available. Unless noted, we use 3-month ahead expectations. Inflation rates are expressed by the year-on-year rate of change in the CPI (excluding perishables). For each, average inflation expectations over next 1, 2, and 10 years are available.

Table 1 provides the descriptive statistics of the QSS. A full sample from July 2004 to October 2013 is divided into four subsamples: (A) July 2004 to December 2007; (B) January 2008 to February 2011; (C) March 2011 to October 2012; and (D) November 2012 to October 2013. Each corresponds to the following periods: (A) before the global financial crisis; (B) during the financial crisis and before the Great East Japan Earthquake; (C) between the earthquake and the introduction of Abenomics; and (D) after the introduction of Abenomics.

\subsection{Bond-yields Expectations}

JGB yields at all maturities declined throughout the sample. These hint at either increasing perceptions toward future accommodative monetary policy or decreasing natural interest rates. Importantly, these are not the result of something specific in the period 
after the introduction of Abenomics. Skewness has not been significantly different from zero. Respondents throughout this sample were not very concerned about the default risk of JGBs. Figure 3 shows times-series bond yields for mean as well as 2.5, 10, 50 (median), 90, and 97.5 percentile points. As consistent with the actual movements in Figure 2, expectations for 5-, 10- and 20-year interest rates jumped up to the level of mid 2012, despite the QQME in April 2013. At the same time, cross-sectional variations in the market participants' forecasts for bond yields became larger. Albeit temporarily, the QQME increased market uncertainty.

\subsection{Inflation Expectations}

The contribution of consumption tax is implicitly included in the QSS in inflation expectations. ${ }^{11}$ In August 2012, the upper-house parliament passed a tax bill to raise the consumption-tax rate from 5\% to 8\% in April 2014 and then to 10\% in September 2015. Figure 4 evaluates the maximum possible contribution of the tax rises on inflation expectations. ${ }^{12}$ The first rise in inflation expectations is considered when the law was passed in August 2012. Its effect was gradual, because inflation expectations are the average over the time horizon. For example, inflation expectations over the next 1 year in April 2013 will reflect only one-twelfth of the effects of the tax rise from $5 \%$ to $8 \%$ in April 2014 .

Short-term inflation expectations increased in sample (D). Those for the next 1 and 2 years rose by $0.4 \%$ and $0.5 \%$, respectively. This may reflect the intended effect of the first arrow, but may also simply reflect contributions from an expected increase in the consumption tax rate as illustrated in Figure 4. Also, long-term inflation expectations are stable at around $1 \%$ throughout the sample. They are well below the new inflation target of $2 \%$ adopted in January $2013 .^{13}$

\footnotetext{
${ }^{11}$ From September 2013, the QSS explicitly asks the respondents to include contributions from consumption tax in their forecasts.

${ }^{12}$ Not all goods are subject to consumption tax.

${ }^{13}$ As Kuroda (2013b) states in December, inflation expectations are formed not only by a forwardlooking element but also by an adaptive or backward-looking element. Such a view was, however, not expressed at the introduction of the QQME.
} 
The last finding is reinforced by Figure 5, which demonstrates that the median of inflation expectations for the next 10 years has hardly increased. It remains at $1 \%$ from 2011 onwards. Compared with the sharp rise in inflation expectations for the 2.5 percentile highest point, the remaining percentiles show much smaller increases. They are below $2 \%$, the new inflation target level. According to Table 1, skewness is positive. These results altogether suggest that an increase in the mean of inflation expectations was driven by the upper tail of the distribution. Even though the inflation target was raised from $1 \%$ to $2 \%$ and the QQME has been introduced, there is no significant increase in median of long-term inflation expectations. ${ }^{14}$ No upheaval in inflation expectations is yet observed.

To compare inflation expectations from other sources, Table 1 includes professional forecasts as well as households' inflation expectations. ${ }^{15}$ While the average of households' inflation expectations is biased upward against the other two surveys, the differences of average inflation expectations over 1-year between the QSS and the ESP are small. As shown in Figure 6, developments in inflation expectations over the 1 year horizon are similar of the three types. Moreover, market expectations measured by the inflation indexed bonds exhibit a similar level of long-term inflation expectations to the QSS (Bank of Japan, 2014).

\footnotetext{
${ }^{14}$ The Survey of Professional Forecasters and the Livingston Survey, which collect outlook mainly for macroeconomic variables by the Federal Reserve Bank of Philadelphia, also report not mean but median across forecasters.

${ }^{15}$ The ESP forecast is a monthly survey of about 40 economists on various macroeconomic variables, which is conducted by the Japan Center for Economic Research. Among many survey items, we focus on the forecasts of average inflation expectations over the next 1 year. Inflation rates are expressed by the year-on-year rate of change in the CPI (excluding perishables). In addition to the professionals' forecasts, we present households' inflation expectations from the Consumer Confidence Survey (CCS) which is provided by the Cabinet Office in Japan. The CCS asks households to provide their price expectations one year from now. In order to transform an original, qualitative answer into a quantitative indicator, we follow the weighted average method by the Bank of Japan (2014).
} 


\section{Evaluating Monetary Policy Stance}

Using the QSS data, we look at market perceptions on monetary policy stance. The QSS contains individual forecasts on both interest and inflation rates. By using such cross-sectional information, monetary policy stance or the policy reaction function can be estimated even with a short sample.

A monetary policy reaction is assumed to be

$$
i_{t}^{S}=\rho i_{t-1}^{S}+\alpha \pi_{t}
$$

where $i_{t}^{S}$ and $\pi_{t}$ denote short-term policy interest and inflation rates, respectively. Both are expressed in annualized rates. Time aggregation leads to

$$
\mathbb{E}_{t, j} \sum_{\tau=1}^{k} i_{t+\tau}^{S}=\rho \mathbb{E}_{t, j} \sum_{\tau=1}^{k} i_{t+\tau-1}^{S}+\alpha \mathbb{E}_{t, j} \sum_{\tau=1}^{k} \pi_{t+\tau},
$$

or

$$
\mathbb{E}_{t, j} i_{t+k}^{L}=\rho \mathbb{E}_{t, j} i_{t+k-1}^{L}+\alpha \mathbb{E}_{t, j} \pi_{t+k}^{L}
$$

where $i_{t+k}^{L}$ and $\pi_{t+k}^{L}$ denote long-term bond yields and average inflation expectations over the next $k$ periods, respectively. $\mathbb{E}_{t, j}$ is an investor $j$ 's expectation operator given information available at $t$.

Even though the zero lower bound constrains a short-term interest rate, a main transmission channel still works through forward guidance about future interest rates. That said, monetary policy reaction may not be stable throughout sample periods. Our aim is to examine the (in)stability of the monetary policy reaction by estimating the relationship in equation (1), which is based on the Taylor type rule. If there is regime change, for example, associated with a shift of operational instrument from interest rates to monetary base, then observed monetary policy reaction, or an observed relationship between interest rates and inflation rates, as in equation (1), will change. We investigate such a possibility by dividing sample periods.

An estimation of the expected policy reaction follows the spirit of Kim and Pruitt (2013). ${ }^{16}$ They aim to estimate the policy reaction function under the zero lower bound.

\footnotetext{
${ }^{16}$ See also Aoki and Ueno (2012) for the study that uses forward rate curves to overcome the problem due to the zero lower bound.
} 
The censoring problem due to the zero lower bound is cleared by using the survey forecasts for the period when policy interest rates are positive. In our paper, use of the forecasts on the long-term bond yields and long-term inflation expectations allows us to evaluate the monetary policy stance perceived by market participants. Even though the long-term bond yields are very low, they are positive and show some dynamics depending on macroeconomic environments. We can still observe the time-variations in the monetary policy stance perceived by the market participants.

To be precise, we estimate four variants of equation (1):

$$
\begin{aligned}
\text { (I) }: & \mathbb{E}_{t, j} i_{t+k+3 \rightarrow t+k^{\prime}+3, j}^{L}=c+\alpha \mathbb{E}_{t, j} \pi_{t+k \rightarrow t+k^{\prime}, j}^{L}+\varepsilon_{t, j}, \\
(\mathrm{II}): & \mathbb{E}_{t, j} i_{t+k+3 \rightarrow t+k^{\prime}+3, j}^{L}=c_{j}+\alpha \mathbb{E}_{t, j} \pi_{t+k \rightarrow t+k^{\prime}, j}^{L}+\varepsilon_{t, j}, \\
(\mathrm{III}): & \mathbb{E}_{t, j} i_{t+k+3 \rightarrow t+k^{\prime}+3, j}^{L}=c+\rho i_{t+k \rightarrow t+k^{\prime}}^{L}+\alpha \mathbb{E}_{t, j} \pi_{t+k \rightarrow t+k^{\prime}, j}^{L}+\varepsilon_{t, j}, \\
(\mathrm{IV}): & \mathbb{E}_{t, j} i_{t+k+3 \rightarrow t+k^{\prime}+3, j}^{L}=c_{j}+\rho i_{t+k \rightarrow t+k^{\prime}}^{L}+\alpha \mathbb{E}_{t, j} \pi_{t+k \rightarrow t+k^{\prime}, j}^{L}+\varepsilon_{t, j},
\end{aligned}
$$

where $c_{j}$ represents a fixed effect for investors. Variables with subscripts $t+k \rightarrow t+k^{\prime}$ indicate expectations from period $t+k$ to $t+k^{\prime}$, where we set $\left(k, k^{\prime}\right)$ at $(0,24)$ months for expectations over 2 years, at $(0,120)$ for those over 10 years, and at $(24,120)$ for those from 2 to 10 years. The last specification alleviates the estimation problem due to the zero lower bound most effectively, because it does not use short-term interest rates that are severely constrained by the zero lower bound. ${ }^{17}$ The subscript of the interest rate starts with $t+3$, because 3 -month ahead expectations are used following the questionnaire of the QSS. In (III) and (IV), $i_{t \rightarrow t+k}^{L}$ indicates actual long-term bond yields for the maturity of $k$. We estimate these four equations for four subsamples (A) to (D) in Table 1.

Both $\alpha$ and $\rho$ contain information about monetary policy stance. Parameter $\alpha$ should exceed unity to satisfy the Taylor principle, ${ }^{18}$ but can be below unity if monetary policy commits to keeping low interest rates or term premium is time-varying. ${ }^{19}$ As will be

\footnotetext{
${ }^{17}$ The censoring problem is not entirely resolved, because a current short-term interest rate is constrained at zero and future short-term interest rates are also constrained with a positive probability. See Section 4.2.2 for the possible effects from this censoring problem on our estimates.

${ }^{18}$ In equations (III) and (IV), $\alpha$ should exceed $1 /(1-\rho)$.

${ }^{19}$ Contrary to inflation expecatations, forecasts on bond yields are about the market rate. Therefore,
} 
shown theoretically in Section 4.2.2, a small $\alpha$ implies that a central bank will not react strongly to a rise in inflation expectations, and hence, exhibit more behind-thecurve responses of monetary policy. Parameter $\rho$ indicates monetary policy inertia. A higher $\rho$ represents more committed policy for future easing. If $\rho=1$, monetary policy corresponds to price-level targeting. If $\rho>1$, the monetary policy rule entails a superinertia and a deflationary trap can be eliminated, as is shown by Sugo and Ueda (2008b). Parameter $c$, an intercept in the equations, illustrates a term premium and/or a natural rate of interest.

Estimates of $\alpha$ and $\rho$ are subject to two identification challenges, as Sections 4.2.1 and 4.2.2 discuss. We do not, thus, claim that our estimates are precise. However, this is not a critical point influencing the main aim of this paper. Rather, we are interested in whether there is any regime change in monetary policy or significant enhancement of the forward guidance, that is, we are interested in the dynamic properties of these parameters rather than their sizes.

\subsection{Estimation Results}

Tables 2, 3, and 4 demonstrate that monetary policy reaction, captured by the coefficient of the interest rate on the inflation rate, $\alpha$, is overall positive and smaller than unity. Also, it exhibits a declining trend. In particular, $\alpha$ becomes insignificant in some specifications in the subsample (C) and (D). The difference in $\alpha$ before and after the introduction of Abenomics, namely, between subsamples (C) and (D), is the smallest among others. $\alpha$ declines significantly from subsample (C) to (D) in only 3 out of 12 regressions.

Figures 7 and 8 display scattered diagrams between inflation and bond-yield expectations. The top panel plots expectations of full samples, while the remaining four panels are those of the four subsamples (A) to (D). The solid curve represents non-parametric kernel smoothing regression of $\alpha$. The slope has flattened, suggesting that monetary policy reaction to inflation rates weakened. A preliminary check confirms that the differences in $\alpha$ between subsample (C) and (D) are minuscule. ${ }^{20}$

there can possibly exist a bias due to beauty contest. This may lower the estimate of $\alpha$.

${ }^{20}$ Even though perceived reactions remain flat between different subsamples, the rightward shifts of 
Developments in parameter $\alpha$ suggest that, even before November 2012, markets had anticipated that the Bank of Japan would keep the policy interest rate very low, even when inflation rates increased in the future. In subsample $(\mathrm{C})$, the perceived policy response is almost flat. ${ }^{21}$ Commitment to future monetary easing had already intensified prior to Abenomics and little room existed for further forward guidance at the time of its introduction of Abenomics. Even long-term bond yields have been already close to the zero lower bound. That is, Japan may be considered to be constrained by a long-term liquidity trap, where not only short-term but also long-term bond yields are constrained by the zero lower bound.

According to Sargent's (1982) criteria for regime change, it should be appropriate to state that no significant regime shift in monetary policy has been observed in the QSS, since the introduction of Abenomics or the QQME. In some specifications, $\alpha$ declines from subsample $(\mathrm{C})$ to $(\mathrm{D})$, but the change is marginal. Abenomics may be thus interpreted as slightly intensifying the Bank of Japan's ongoing attempts toward monetary accommodation, but not as inducing policy regime change. ${ }^{22}$

Regarding the policy persistence, $\rho$ is near unity throughout the samples. The perceived monetary policy stance is thus close to superinertial or price-level targeting. In this respect, the economy seems to avoid the steady state multiple equilibria or the deflationary trap advocated by Benhabib, Schmitt-Grohe and Uribe (2002). However, this evaluation is subject to two identification challenges mentioned below.

the plots, namely an increase in inflation expecations given constant long-term bond yields, may be considered as a consequence of policy regime shift. This can be interpreted as the situation where the central bank intensifies the forward guidance through a decrease in $u$ in Section 4.2.2. No significant rightward shift is, however, observed between subsamples (C) and (D).

${ }^{21}$ Theoretically, this situation should have created an economic boom. The fact that inflation rates are still not very high implies the existence of the forward guidance puzzle of Del Negro, Giannoni and Patterson (2012).

${ }^{22}$ The estimation result that forecasts on medium- and long-term interest rates hardly respond to changes in inflation expectations during subsamples (C) and (D) may reflect the pessimistic outlook of market participants for prolonged deflation. Kato and Takeda (2004) argue that a credible commitment to maintaining a low interest rate policy results in higher (long-term) interest rates and stronger economic activity in the following period. Yet, if this is the case, long-term inflation expectations must rise immediately. 
The term premium and/or the natural rate of interest, measured by an intercept $c$, has been decreasing. In equations (II) and (IV), $c$ indicates the average of fixed effects $c_{j}$. The downtrend of $c$ may be explained by the following three factors. First, a decline in term premiums is caused by a decrease in inflation uncertainty. Wright (2011) finds that the term premium components of forward rates trended down in industrialized countries over the last 20 years and concludes that it owes in part to declining inflation uncertainty. The second factor is a downtrend in potential growth rates. Third, the asset purchasing program by the Bank of Japan, including the QQME, which was aimed at lowering risk premium of asset prices may have worked. According to the third view, a decline in $c$ from subsample (C) to (D) is interpreted as evidence supporting the role of the QQME. However, again the size of the decline is milder than that of the previous periods, indicating regime shift is not observed.

Our estimation result also suggests a trade-off between goals in the short and long run. The central bank strengthened their commitment to maintaining very low interest rates in order to rally the economy in the short run. The dissemination of this policy may work positively in terms of people's perception, but can increase risks in the long run. ${ }^{23}$ An excessive behind-the-curve approach may violate the Taylor principle and cause indeterminacy. Inflation expectations may become uncontrollable in the future.

\subsection{Identification Issue}

The aim of this paper is to examine if there is any monetary policy regime change or any significant change in the degree of the forward guidance, not to obtain precise estimates on monetary policy stance. Nevertheless, it is important to discuss identification issues regarding endogeneity and a zero lower bound.

\footnotetext{
${ }^{23}$ A large amount of Japanese government bonds purchased by the Bank of Japan may also have increased the possibility of monetization of government finance. This may hamper governmental attempts toward fiscal sustainability.
} 


\subsubsection{Endogeneity}

Estimating equation (1) with expectations is subject to endogeneity. This is because expectations on both interest and inflation rates are endogenous variables. Let us examine here under which circumstances estimation results as above replicate the coefficients in policy reactions using a simple general equilibrium model.

According to the simple New Keynesian model, the economy is expressed by three equations: the Taylor rule, the Phillips curve, and the IS (Euler) curve:

$$
\begin{gathered}
\hat{\imath}_{t}=\alpha \hat{\pi}_{t}+u_{t}, \\
\hat{\pi}_{t}=\beta \mathbb{E}_{t} \hat{\pi}_{t+1}+\kappa \hat{x}_{t}+z_{t},
\end{gathered}
$$

and

$$
\hat{x}_{t}=\mathbb{E}_{t} \hat{x}_{t+1}-\sigma\left(\hat{\imath}_{t}-\mathbb{E}_{t} \hat{\pi}_{t+1}\right)+v_{t}
$$

where $\hat{\imath}_{t}, \hat{\pi}_{t}$, and $\hat{x}_{t}$ indicate log-linearized deviations of the short-term nominal interest rate, the inflation rate, and the output gap at $t$, respectively. Parameters $\alpha, \beta$, and $\sigma$ represent the coefficient of the Taylor rule on the inflation rate, a discount factor, and the intertemporal elasticity of substitution, respectively. Exogenous shocks are described by a monetary policy shock $u_{t}$, a markup shock $z_{t}$, and a real interest rate shock $v_{t}$.

To enable analytical investigations, we assume that exogenous shocks hit the economy only at $t=1$ and 2 . The economy returns to its steady state at $t=3$, that is, $u_{t}=z_{t}=$ $v_{t}=0$ for $t \geq 3$. We can obtain a rational expectation equilibrium as follows:

$$
\begin{gathered}
\hat{\imath}_{1}=\mathbb{E}_{t} \frac{-\sigma \alpha \kappa(1+\beta+\sigma \kappa) u_{2}+\alpha[\beta+\kappa \sigma(1-\alpha)] z_{2}+\alpha \kappa(1+\beta+\sigma \kappa) v_{2}}{(1+\sigma \alpha \kappa)^{2}}+\frac{u_{1}+\alpha z_{1}+\alpha \kappa v_{1}}{1+\sigma \alpha \kappa}, \\
\hat{\pi}_{1}=\mathbb{E}_{t} \frac{-\sigma \kappa(1+\beta+\sigma \kappa) u_{2}+[\beta+\kappa \sigma(1-\alpha)] z_{2}+\kappa(1+\beta+\sigma \kappa) v_{2}}{(1+\sigma \alpha \kappa)^{2}}+\frac{-\sigma \kappa u_{1}+z_{1}+\kappa v_{1}}{1+\sigma \alpha \kappa}, \\
\hat{\imath}_{2}=\frac{u_{2}+\alpha z_{2}+\alpha \kappa v_{2}}{1+\sigma \alpha \kappa},
\end{gathered}
$$

and

$$
\hat{\pi}_{2}=\frac{-\sigma \kappa u_{2}+z_{2}+\kappa v_{2}}{1+\sigma \alpha \kappa} .
$$

Corresponding dependent and explanatory variables in the variants of equation (1) are the long-term interest rate $\left(\hat{\imath}_{1}+\mathbb{E}_{1} \hat{\imath}_{2}\right) / 2$ and the long-term inflation expectation 
$\left(\hat{\pi}_{1}+\mathbb{E}_{1} \hat{\pi}_{2}\right) / 2$, respectively. It is immediately clear that as long as the monetary policy shocks $u_{1}$ and $u_{2}$ are zero, the estimate of $\alpha$ equals the true coefficient of the Taylor rule. So, the validity of the interpretation based on the estimation of equation (1) depends on whether or not the contribution of monetary policy shocks to the economy is small. In this regard, Sugo and Ueda (2008a) estimate a medium-scale DSGE model for Japan and report that the majority of short-term fluctuations in the inflation rate are driven by markup and technology shocks. ${ }^{24}$ Also, the fact that $\alpha$ is basically positive implies that our interpretation has a small margin of inaccuracy. This is because when only monetary policy shocks are present, the estimate of $\alpha$ becomes negative.

In order to understand the possible estimation bias from monetary shock visually, we simulate the standard new Keynesian model above and estimate $\alpha$ with different relative size of monetary policy shocks to other shocks. The calibrated parameters are as follows: $\alpha=1.5 ; \beta=0.99$; and $\sigma=1$. Top two panels in Figure 9 display how estimated parameter $\alpha$ changes with an increasing monetary policy shock. The autoregressive parameter of shocks is set at 0 and 0.8 , respectively, for left and right panels. These panels illustrate that $\alpha$ declines, when the contribution from the monetary policy shock becomes larger or the persistence of shocks becomes smaller. Suppose that regime changes in monetary policy, including the introduction of the QQME, entail a relative increase in the contribution of the monetary policy shock. This certainly lowers the estimate of $\alpha$, which is consistent with actual changes in the estimate of $\alpha$. However, it is fair to point out that the size of regression residuals reported in Tables 2 and 3 decreases, rather than increases, from subsample (A) to (D). The bottom two panels in Figure 9 indicate a change in estimated $\alpha$ when short-term interest and inflation rates are used for estimation. Basically, the bias stemming from endogeneity is the same. ${ }^{25}$

\footnotetext{
${ }^{24}$ Naturally, in the long-term, one type of monetary policy shock, an inflation target shock, influences inflation rates dominantly.

${ }^{25}$ We also confirm that, as long as the monetary policy shock is not comparatively large, $\rho$ is correctly estimated. A relative increase in the shock lowers the estimate of $\rho$ to zero.
} 


\subsubsection{Zero Lower Bound}

Another important challenge in evaluating monetary policy stance stems from the zero lower bound of nominal interest rates. Explicit consideration of the zero lower bound transforms the previous three equations into

$$
\begin{gathered}
\hat{\imath}_{t}=\max \left(0, \bar{r}+\alpha \hat{\pi}_{t}+u_{t}\right) . \\
\hat{\pi}_{t}=\beta \mathbb{E}_{t} \hat{\pi}_{t+1}+\kappa \hat{x}_{t}+z_{t},
\end{gathered}
$$

and

$$
\hat{x}_{t}=\mathbb{E}_{t} \hat{x}_{t+1}-\sigma\left(\hat{\imath}_{t}-\mathbb{E}_{t} \hat{\pi}_{t+1}-\bar{r}\right)+v_{t} .
$$

To have a positive interest rate off the zero lower bound, we introduce $\bar{r}>0$ as a steady-state rate of real interest. We assume discretionary policy for $t \geq 3$. This makes $\pi_{t}=x_{t}=0$ and $i_{t}=\bar{r}$ for $t \geq 3$ after exogenous shocks disappear. We also assume that a negative shock of $v_{1}$ is sufficiently large to bring the nominal interest rate $\hat{\imath}_{1}$ to the zero lower bound.

Backward induction yields the following rational expectation equilibrium. For $t=2$, $\hat{\imath}_{2}=0$ when

$$
(1+\sigma \alpha \kappa) \bar{r}+\alpha \kappa v_{2}+\alpha z_{2}+u_{2}<0 .
$$

First, when equation (2) is satisfied, we have

$$
\begin{gathered}
\hat{\imath}_{2}=0 \\
\hat{\pi}_{2}=\kappa\left(\sigma \bar{r}+v_{2}\right)+z_{2} .
\end{gathered}
$$

Second, when equation (2) is not satisfied, we have

$$
\begin{gathered}
\hat{\imath}_{2}=\bar{r}+\frac{\alpha \kappa v_{2}+\alpha z_{2}+u_{2}}{1+\sigma \alpha \kappa}, \\
\hat{\pi}_{2}=\frac{\kappa v_{2}+z_{2}-\kappa \sigma u_{2}}{1+\sigma \alpha \kappa} .
\end{gathered}
$$

For $t=1$,

$$
\begin{gathered}
\hat{\imath}_{1}=0, \\
\hat{\pi}_{1}=(\beta+\kappa \sigma) \mathbb{E}_{1} \hat{\pi}_{2}-\kappa \sigma \mathbb{E}_{1}\left(\hat{\imath}_{2}-\bar{r}\right)+\kappa \sigma \bar{r}+\kappa v_{1}+z_{1}+\kappa \mathbb{E}_{1} v_{2} .
\end{gathered}
$$


The long-term expectation for the inflation rate is thus given by

$$
\begin{aligned}
\hat{\pi}_{1}+\mathbb{E}_{1} \hat{\pi}_{2} & =(1+\beta+\kappa \sigma)\left\{\begin{array}{c}
\left(1-\operatorname{Pr}\left(\hat{\imath}_{2}=0\right)\right) \mathbb{E}_{1}\left(\frac{\kappa v_{2}+z_{2}-\kappa \sigma u_{2}}{1+\sigma \alpha \kappa} \mid \hat{\imath}_{2}>0\right) \\
+\operatorname{Pr}\left(\hat{\imath}_{2}=0\right) \mathbb{E}_{1}\left(\kappa\left(\sigma \bar{r}+v_{2}\right)+z_{2} \mid \hat{\imath}_{2}=0\right)
\end{array}\right\} \\
& -\kappa \sigma\left\{\begin{array}{c}
\left(1-\operatorname{Pr}\left(\hat{\imath}_{2}=0\right)\right) \mathbb{E}_{1}\left(\frac{\alpha \kappa v_{2}+\alpha z_{2}+u_{2}}{1+\sigma \alpha \kappa} \mid \hat{\imath}_{2}>0\right) \\
-\operatorname{Pr}\left(\hat{\imath}_{2}=0\right) \bar{r}
\end{array}\right\} \\
& +\kappa \sigma \bar{r}+\kappa v_{1}+z_{1}+\kappa \mathbb{E}_{1} v_{2} .
\end{aligned}
$$

The long-term interest rate is given by

$$
\begin{aligned}
\hat{\imath}_{1}+\mathbb{E}_{1} \hat{\imath}_{2} & =\mathbb{E}_{1} \hat{\imath}_{2} \\
& =\left(1-\operatorname{Pr}\left(\hat{\imath}_{2}=0\right)\right) \mathbb{E}_{1}\left(\bar{r}+\frac{\alpha \kappa v_{2}+\alpha z_{2}+u_{2}}{1+\sigma \alpha \kappa} \mid \hat{\imath}_{2}>0\right) .
\end{aligned}
$$

To evaluate equations (3) and (4), we further assume the following process of exogenous shocks. There is no supply shock: $z_{1}=z_{2}=0$. Real interest rate shocks follow $v_{1}=v_{-}<0$ at $t=1$, and $v_{2}=v_{-}<0$ with the probability of $p$ and $v_{2}=v_{+}>0$ with the probability of $1-p$ at $t=2$. The monetary policy shock $u_{2}$ at $t=2$ is given by $u_{2}=u \leq 0$, where negative $u$ indicates commitment to maintaining a low interest rate after an adverse shock disappears.

Under these assumptions, we have the following results. If

$$
u<-(1+\sigma \alpha \kappa) \bar{r}-\alpha \kappa v_{+}
$$

it yields $\hat{\imath}_{2}=0$, even when an adverse shock disappears $\left(v_{2}=v_{+}\right)$at $t=2$. Otherwise, $\hat{\imath}_{2}>0$. First, the probability $\operatorname{Pr}\left(\hat{\imath}_{2}=0\right)$ equals 1 if $u<-(1+\sigma \alpha \kappa) \bar{r}-\alpha \kappa v_{+}$, and $p$ otherwise. Second, from equation (4), the long-term interest rate reads

$$
\hat{\imath}_{1}+\mathbb{E}_{1} \hat{\imath}_{2}=\left\{\begin{array}{c}
0 \quad \text { if } u<-(1+\sigma \alpha \kappa) \bar{r}-\alpha \kappa v_{+} \\
(1-p)\left(\bar{r}+\frac{\alpha \kappa v_{+}+u}{1+\sigma \alpha \kappa}\right) \quad \text { if } u \geq-(1+\sigma \alpha \kappa) \bar{r}-\alpha \kappa v_{+}
\end{array} .\right.
$$

Third, equation (3) suggests the long-term expectation for the inflation rate becomes

$$
\begin{aligned}
\hat{\pi}_{1}+\mathbb{E}_{1} \hat{\pi}_{2} & =\{(2+\beta+\kappa \sigma) p+1\} \kappa v_{-} \\
& +(2+\beta+\kappa \sigma)(1-p) \kappa v_{+} \\
& +(3+\beta+\kappa \sigma) \kappa \sigma \bar{r}
\end{aligned}
$$


if $u<-(1+\sigma \alpha \kappa) \bar{r}-\alpha \kappa v_{+}$and

$$
\begin{aligned}
\hat{\pi}_{1}+\mathbb{E}_{1} \hat{\pi}_{2} & =-(2+\beta+\kappa \sigma)(1-p) \frac{\kappa \sigma}{1+\sigma \alpha \kappa} u \\
& +\{(2+\beta+\kappa \sigma) p+1\} \kappa v_{-} \\
& +\frac{2+\beta+\kappa \sigma}{1+\sigma \alpha \kappa}(1-p) \kappa v_{+} \\
& +\{(2+\beta+\kappa \sigma) p+1\} \kappa \sigma \bar{r}
\end{aligned}
$$

if $u \geq-(1+\sigma \alpha \kappa) \bar{r}-\alpha \kappa v_{+}$.

When we use cross-sectional data on long-term inflation expectations and bond-yield expectations from the QSS, the estimate $\alpha$ is given by

$$
\widehat{\alpha}=\frac{\operatorname{Cov}\left(\hat{\pi}_{1}+\mathbb{E}_{1} \hat{\pi}_{2}, \hat{\imath}_{1}+\mathbb{E}_{1} \hat{\imath}_{2}\right)}{\operatorname{Var}\left(\hat{\pi}_{1}+\mathbb{E}_{1} \hat{\pi}_{2}\right)} .
$$

Note that Cov and Var indicate the covariance and variance, respectively, of shocks across respondents. Each respondent is assumed to have differing expectations about shocks.

Hence, the estimate $\alpha$ equals 0 if $u<-(1+\sigma \alpha \kappa) \bar{r}-\alpha \kappa v_{+}$and

$$
\widehat{\alpha}=\frac{-\frac{1-p}{1+\sigma \alpha \kappa} \frac{(2+\beta+\kappa \sigma)(1-p) \kappa \sigma}{1+\sigma \alpha \kappa} \operatorname{Var}(u)+\alpha(2+\beta+\kappa \sigma)\left\{\frac{(1-p) \kappa}{1+\sigma \alpha \kappa}\right\}^{2} \operatorname{Var}\left(v_{+}\right)}{\left\{\frac{(2+\beta+\kappa \sigma)(1-p) \kappa \sigma}{1+\sigma \alpha \kappa}\right\}^{2} \operatorname{Var}(u)+\{(2+\beta+\kappa \sigma) p+1\}^{2} \kappa^{2} \operatorname{Var}\left(v_{-}\right)+\left\{\frac{(2+\beta+\kappa \sigma)(1-p) \kappa}{1+\sigma \alpha \kappa}\right\}^{2} \operatorname{Var}\left(v_{+}\right)}
$$

if $u \geq-(1+\sigma \alpha \kappa) \bar{r}-\alpha \kappa v_{+}$.

Equation (7) reveals how the estimate $\alpha$ depends on the economic structure. Most importantly, when $u$ is massively negative, $\widehat{\alpha}$ is zero. Parameter $u$ indicates commitment to maintaining a low interest rate. Stronger commitment or lower $u$ increases the possibility that the interest rate is zero at $t=2$. This lowers the monetary policy reaction to inflation to zero. Also, as the probability of the deflationary equilibrium, $p$, increases, $\widehat{\alpha}$ moves closer to zero, as long as $\operatorname{Var}\left(v_{-}\right)>0$. This increases the possibility of the zero interest rate at $t=2$.

We, however, also have reservations about this interpretation. When the contribution of the real interest rate shock, $\operatorname{Var}\left(v_{+}\right)$, is sufficiently large, $\widehat{\alpha}$ converges to $\alpha /(2+\beta+\kappa \sigma)$. 
The slope is positive, but not equal to $\alpha$. It becomes flatter. To the contrary, when the contribution of the monetary policy shock, $\operatorname{Var}(u)$, is sufficiently large, $\widehat{\alpha}$ is negative.

Equations (5) and (6) illustrate the difficulty in recovering inflation expecations under the long-term liquidity trap. If the natural rate of interest is high, $u \geq-(1+\sigma \alpha \kappa) \bar{r}-\alpha \kappa v_{+}$ is satisfied, and equation (6) holds. In such a case, intensifying forward guidance through a decrease in $u$ raises inflation expecations. However, unless the above condition is satisfied, long-term bond yields are zero and inflation expecations are determined by equation (5). A decrease in $u$ has no effect on inflation expecations.

\section{Concluding Remarks}

In this paper, we have evaluated monetary policy stance using the panel survey forecasts of the QSS. Long-term inflation expectations have not risen significantly. Since the mid 2000s, the central bank has intensified its commitment to maintaining low interest rates in the future. No abrupt regime change has been observed before or after the introduction of Abenomics.

Admittedly, this paper has been silent on why financial markets improved during the implementation of the policies termed Abenomics. The scope of this paper was limited to the market perceptions of the monetary policy stance among QSS respondents. Thus, we cannot deny the possibility that the first arrow of the Abenomics could work via other channels, that are not through inflation and policy rate expectations. ${ }^{26}$ Although it may not be easy to explain such a channel with existing theory, let us here discuss three possibilities.

The first possibility is that Abenomics influenced market perceptions outside QSS respondents, that is, outside Japan. In that regard, Fukuda (2014) complements our study and examines asymmetric market reactions to Abenomics using intra-day price developments. He convincingly illustrates that foreign investors were far more aggressive purchasers of Japanese stocks and US dollars against Japanese yen than local investors. Yet, we still need a theory why and how such actions by foreign investors were induced.

\footnotetext{
${ }^{26}$ There may exist the (expectations of) Olympic effects. Rose and Spiegel (2011) show that hosting Olympic has positive impacts on exports.
} 
Second, quantitative easing, as one kind of monetary policy, may have some impact on real economic variables through its effects on asset prices via a portfolio balance effect coined by Tobin (1958), which is based on preferred habitat motives. Recently, several studies investigate the relationship between unconventional monetary policy and risks in the financial markets. Gagnon, Raskin, Remache and Sack (2011) and Joyce, Lasaosa, Stevens and Tong (2011) find some positive effects of unconventional monetary policy in reducing the term premium in long-term bond yields. Orphanides and Wieland (2000) propose a model which includes "the portfolio balance channel through which changes in relative money supplies influence the exchange rate." Further developments in such studies have the potential to clarify the structural relationship between aggressive quantitative easing under the liquidity trap and risk premium in financial markets. If the portfolio balance channel works effectively in the bond market, however, its effects should appear as significant changes in market perceptions in the QSS. Also, regarding such an effect to other financial variables than long-term bonds, Orphanides and Wieland (2000) state that "the quantitative magnitude of any such effect may be very small and is certainly highly uncertain." Thus, it is still uncertain whether such a portfolio balance channel could reverse deflationary expectation. ${ }^{27}$

The third channel is through fiscal policy, or more broadly, strategic interaction between the central bank and the government. Indeed, Eggertsson (2008) points out that fiscal regime change stopped chronic deflation in the United States. Sargent (1981, 1982) illustrates the important roles of governments in stopping or not stopping inflation. According to the fiscal theory of price level, fiscal theory dominantly determines a general price level (Leeper, 1991; Woodford, 1995; Cochrane 2011). The accumulation of government debts or irresponsible fiscal policy, with the combination of passive monetary

\footnotetext{
${ }^{27}$ Woodford (2012) states that "[u]nfortunately, neither of the theories typically relied upon to explain why that should be the case - the quantity-theoretic doctrine that expansion of the monetary base must inevitably lead to increased aggregate nominal spending, or the particular kind of preferred-habitat model of the term structure that would imply the existence of a "duration-risk channel" — has a robust theoretical basis (in the sense of following from hypotheses that seem likely to be true, rather than relying upon special assumptions that might nonetheless conceivably be true) or finds much support from experience thus far."
} 
policy, generates inflation to maintain the real fiscal balance. Cochrane (2011) concludes "that the central bank may be almost powerless to avoid deflation or inflation."

Any public policy should have sound theoretical backgrounds. Otherwise, the society would lose the way to choose good policies among others. Modern macroeconomics emphasizes the importance of expectation management for public policy. Even though some channels like those discussed above may work to influence market perceptions, a clear and stable structural relationship between controllable tools by public policy and the expectation must always exist. The central banks cannot be as entrepreneurial as private firms. If such a relationship does not exist, policy cannot be credible and expectation may become uncontrollable. Policy makers and academia must be aware of such a risk by holding a long-term perspective without being complacent about shortterm recovery.

Finally but most importantly, our study implies a new challenge for central banks. To date, theoretically, the only effective tool left for the central bank under the liquidity trap is forward guidance or signaling role of the quantitative easing. Yet, as of now in Japan, due to already highly enhanced commitments for future lower interest rates, even long-term bond yields have been close to be constrained by the zero lower bound. How could a central bank design effective policy tools under such a long-term liquidity trap? This important theoretical question is left for our future research.

\section{References}

[1] Albanesi, Stefania, Chari, Varadarajan, and Christiano, Lawrence, "Expectation Traps and Monetary Policy," Review of Economic Studies, 70(4), 715-741, 2003.

[2] Aoki, Kosuke, and Ueno, Yoichi, "Identification of Structural Shocks under the Zero Lower Bound on Nominal Interest Rates," Bank of Japan Working Paper Series 12E-8, 2012.

[3] Bank of Japan, "Monthly Report of Recent Economic and Financial Developments 2014," January 2014, 2014. 
[4] Bauer, Michael, and Rudebusch, Glenn, "The Signaling Channel for Federal Reserve Bond Purchases," Federal Reserve Bank of San Francisco Working paper Series, 2011-21, 2013.

[5] Benhabib, Jess, Schmitt-Grohe, Stephanie, and Uribe, Martin, "Avoiding Liquidity Traps," Journal of Political Economy, 110(3), 535-563, 2002.

[6] Bhattarai, Saroj, Eggertsson, Gauti, and Gafarovy, Bulat, "Time Consistency and the Duration of Government Debt: A Signalling Theory of Quantitative Easing," mimeo, 2014.

[7] Clarida, Richard, Gali, Jordi, and Gertler, Mark, "Monetary Policy Rules And Macroeconomic Stability: Evidence And Some Theory," Quarterly Journal of Economics, 115(1), 147-180, 2000.

[8] Cochrane, John H., "Understanding Policy in the Great Recession: Some Unpleasant Fiscal Arithmetic," European Economic Review, 55, 2-30, 2011.

[9] Del Negro, Marco, Giannoni, Marc, and Patterson, Christina, "The Forward Guidance Puzzle," Staff Reports 574, Federal Reserve Bank of New York, 2012.

[10] Eggertsson, Gauti, "Great Expectations and the End of the Depression," American Economic Review, 98 (4), 1476-1516, 2008.

[11] Eggertsson, Gauti and Woodford, Michael, "The Zero Bound on Interest Rates and Optimal Monetary Policy," Brookings Papers on Economic Activity 34 (2003-1), 139-235, 2003.

[12] Fujiki, Hiroshi and Shiratsuka, Shigenori, "Policy Duration Effect under the Zero Interest Rate Policy in 1999-2000: Evidence from Japan's Money Market Data," Monetary and Economic Studies, 20(1), 1-31, 2002.

[13] Fujiwara, Ippei, "Is There a Direct Effect of Money?: Money's Role in an Estimated Monetary Business Cycle Model of the Japanese Economy," Japan and the World Economy, 19(3), 329-337, 2007. 
[14] Fukuda, Shin-ichi, "Abenomics: Why was it so Successful in Changing Market Expectations?" mimeo, 2014.

[15] Gagnon, Joseph Raskin, Matthew, Remache, Julie, and Sack, Brian, "The Financial Market Effects of the Federal Reserve's Large-Scale Asset Purchases," International Journal of Central Banking, 7(1), 3-43, 2011.

[16] Hausman, Joshua K., Wieland, Johannes F., "Abenomics: Preliminary Analysis and Outlook," mimeo, 2014.

[17] Jung, Taehun, Teranishi, Yuki, and Watanabe, Tsutomu, "Optimal Monetary Policy at the Zero-interest-rate Bound," Journal of Money, Credit and Banking 37(5), 813$835,2005$.

[18] Joyce, Michael A. S., Lasaosa, Ana, Stevens, Ibrahim, and Tong, Matthew, "The Financial Market Impact of Quantitative Easing in the United Kingdom," International Journal of Central Banking, 7(3), 113-161, 2011.

[19] Kamada, Koichiro and Sugo, Tomohiro, "Evaluating Japanese Monetary Policy under the Non-negativity Constraint on Nominal Short-term Interest Rates," the Bank of Japan Working Paper Series 06-E-17, 2006.

[20] Kato, Ryo, and Takeda, Yoko, "Reviewing US Monetary Policy in Disinflation Era: A Primer," the Bank of Japan Working Paper Series 04-E-13, 2004.

[21] Kim, Jinill and Pruitt, Seth, "Estimating Monetary Policy Rules when Nominal Interest Rates are Stuck at Zero," CAMA Working Papers 2013-53, Australian National University, 2013.

[22] Koenig, Evan F., "Real Money Balances and the Timing of Consumption: an Empirical Investigation,” Quarterly Journal of Economics, 105(2), 399-425, 1990.

[23] Krishnamurthy, Arvind, and Vissing-Jorgensen, Annette "The Effects of Quantitative Easing on Interest Rates: Channels and Implications for Policy," Brookings Papers on Economic Activity, 43, 215-287, 2011. 
[24] Kuroda, Haruhiko, "The Bank's Semiannual Report on Currency and Monetary Control," Bank of Japan, June 19, 2013a.

[25] Kuroda, Haruhiko, "Overcoming Deflation and After," Speech at the Meeting of Councillors of Nippon Keidanren (Japan Business Federation) in Tokyo, December $25,2013 b$.

[26] Leeper, Eric M., 'Equilibria Under 'Active' and 'Passive' Monetary and Fiscal Policies," Journal of Monetary Economics, 27, 129-147, 1991.

[27] Lubik, Thomas A. and Frank Schorfheide "Testing for Indeterminacy: An Application to U.S. Monetary Policy," American Economic Review, 94(1), 190-217, 2004.

[28] Nakazono, Yoshiyuki and Ueda, Kozo, "Policy Commitment and Market Expectations: Lessons Learned from Survey Based Evidence under Japan's Quantitative Easing Policy," Japan and the World Economy, 25-26, 102-113, 2013.

[29] Orphanides, Athanasios and Wieland, Volker, "Efficient Monetary Policy Design near Price Stability," Journal of the Japanese and International Economies, 14(4), 327-365, 2000.

[30] Romer, Christina, "It Takes a Regime Shift: Recent Developments in Japanese Monetary Policy through the Lens of the Great Depression," a paper presented at the NBER Macro Annual 2013, 2013.

[31] Rose, Andrew and Spiegel, Mark, "The Olympic Effect," Economic Journal, 121(553), 652-677, 2011.

[32] Sargent, Thomas, "Stopping Moderate Inflations: the Methods of Poincare and Thatcher," FRB Minneapolis Working Paper, 1981.

[33] Sargent, Thomas, "The Ends of Four Big Inflations," in Inflation: Causes and Effects, 1982. 
[34] Sugo, Tomohiro and Ueda, Kozo, "Estimating a Dynamic Stochastic General Equilibrium Model for Japan," Journal of the Japanese and International Economies, 22(4), 476-502, 2008a.

[35] Sugo, Tomohiro and Ueda, Kozo, "Eliminating a Deflationary Trap through Superinertial Interest Rate Rules," Economics Letters, Elsevier, 100(1), 119-122, 2008b.

[36] Temin, Peter, and Wigmore, Barrie A., "The End of One Big Deflation," Explorations in Economic History, 27(4), 483-502, 1990.

[37] Tobin, James, "Liquidity Preference as Behavior Towards Risk." Review of Economic Studies, 67, 65-86, 1958.

[38] Woodford, Michael, "Price-Level Determinacy Without Control of a Monetary Aggregate," Carnegie-Rochester Conference Series on Public Policy, 43, 1-46, 1995.

[39] Woodford, Michael, "Methods of Policy Accommodation at the Interest-Rate Lower Bound," in The Changing Policy Landscape, 2012 Economic Policy Symposium at the Federal Reserve Bank of Kansas City, 185-288, 2012.

[40] Wright, Jonathan, H., "Term Premia and Inflation Uncertainty: Empirical Evidence from an International Panel Dataset," American Economic Review, 101, 1514-1534, 2011. 


\begin{tabular}{|c|c|c|c|c|c|c|c|c|c|}
\hline \multirow{3}{*}{$\begin{array}{l}\text { Item } \\
\text { All sample } \\
2004 / 07 \text { to } 2013 / 10\end{array}$} & \multicolumn{4}{|c|}{ JGB } & \multicolumn{5}{|c|}{ CPI } \\
\hline & \multicolumn{4}{|c|}{ QSS } & \multicolumn{3}{|c|}{ QSS } & \multirow{2}{*}{$\begin{array}{l}\text { ESP } \\
\text { 1-year }\end{array}$} & \multirow{2}{*}{$\begin{array}{l}\text { CCS } \\
\text { 1-year }\end{array}$} \\
\hline & 2-year & 5-year & 10-year & 20-year & 1-year & 2-year & 10-year & & \\
\hline Mean & 0.392 & 0.743 & 1.372 & 2.041 & 0.039 & 0.317 & 0.998 & 0.055 & 1.555 \\
\hline Standard Deviation & 0.328 & 0.413 & 0.365 & 0.239 & 0.674 & 0.612 & 0.652 & & \\
\hline Skewness & 0.907 & 0.469 & -0.179 & -0.448 & -0.052 & 0.122 & 1.813 & & \\
\hline Item & \multicolumn{4}{|c|}{ JGB } & \multicolumn{5}{|c|}{$\mathrm{CPI}$} \\
\hline Subsample (A) & \multicolumn{4}{|c|}{ QSS } & \multicolumn{3}{|c|}{ QSS } & ESP & CCS \\
\hline $2004 / 07$ to $2007 / 12$ & 2-year & 5-year & 10-year & 20-year & 1-year & 2-year & 10-year & 1-year & 1-year \\
\hline Mean & 0.584 & 1.075 & 1.690 & 2.205 & 0.204 & 0.450 & 1.082 & 0.164 & 1.198 \\
\hline Standard Deviation & 0.374 & 0.349 & 0.214 & 0.151 & 0.258 & 0.344 & 0.595 & & \\
\hline Skewness & -0.002 & -0.195 & -0.075 & 0.030 & 0.249 & 1.255 & 1.655 & & \\
\hline Item & \multicolumn{4}{|c|}{$\mathrm{JGB}$} & \multicolumn{5}{|c|}{ CPI } \\
\hline Subsample (B) & \multicolumn{4}{|c|}{ QSS } & \multicolumn{3}{|c|}{ QSS } & $\mathrm{ESP}$ & CCS \\
\hline $2008 / 01$ to $2011 / 02$ & 2-year & 5-year & 10-year & 20-year & 1-year & 2-year & 10-year & 1-year & 1-year \\
\hline Mean & 0.385 & 0.710 & 1.353 & 2.061 & -0.221 & 0.074 & 0.931 & -0.279 & 1.510 \\
\hline Standard Deviation & 0.243 & 0.279 & 0.204 & 0.181 & 0.999 & 0.800 & 0.709 & & \\
\hline Skewness & 0.831 & 0.565 & -0.070 & -0.681 & 0.521 & 0.401 & 2.205 & & \\
\hline Item & \multicolumn{4}{|c|}{ JGB } & \multicolumn{5}{|c|}{ CPI } \\
\hline Subsample (C) & \multicolumn{4}{|c|}{ QSS } & \multicolumn{3}{|c|}{ QSS } & $\mathrm{ESP}$ & CCS \\
\hline $2011 / 03$ to $2012 / 10$ & 2-year & 5-year & 10-year & 20-year & 1-year & 2-year & 10-year & 1-year & 1-year \\
\hline Mean & 0.143 & 0.358 & 1.051 & 1.845 & -0.012 & 0.234 & 0.868 & 0.001 & 1.920 \\
\hline Standard Deviation & 0.045 & 0.113 & 0.168 & 0.159 & 0.314 & 0.391 & 0.607 & & \\
\hline Skewness & 1.230 & 0.278 & 0.013 & 0.261 & -0.678 & 0.629 & 1.699 & & \\
\hline Item & \multicolumn{4}{|c|}{ JGB } & \multicolumn{5}{|c|}{$\mathrm{CPI}$} \\
\hline Subsample (D) & \multicolumn{4}{|c|}{ QSS } & \multicolumn{3}{|c|}{ QSS } & ESP & $\mathrm{CCS}$ \\
\hline $2012 / 11$ to $2013 / 10$ & 2-year & 5-year & 10-year & 20-year & 1-year & 2-year & 10-year & 1-year & 1-year \\
\hline Mean & 0.105 & 0.242 & 0.763 & 1.680 & 0.368 & 0.766 & 1.122 & 0.626 & 2.334 \\
\hline Standard Deviation & 0.037 & 0.098 & 0.143 & 0.159 & 0.558 & 0.622 & 0.669 & & \\
\hline Skewness & 0.343 & 0.639 & -0.208 & -0.825 & 1.941 & 0.860 & 1.428 & & \\
\hline
\end{tabular}

Table 1: Basic descriptive statistics of the QSS data, ESP forecast, and CCS. 


\begin{tabular}{|c|c|c|c|c|c|c|c|c|}
\hline $\begin{array}{l}\text { All sample } \\
2004 / 07 \text { to } 2013 / 10\end{array}$ & $c$ & & $f$ & & o & & $\begin{array}{c}\text { Standard Error } \\
\text { of Regression }\end{array}$ & Observations \\
\hline Equation (I) & $0.331^{* * *}$ & $(0.006)$ & & & $0.190^{* * *}$ & $(0.009)$ & 0.307 & 16435 \\
\hline Equation (II) & $0.339^{* * *}$ & $(0.003)$ & & & $0.162^{* * *}$ & $(0.010)$ & 0.239 & 16435 \\
\hline Equation (III) & $-0.003^{* *}$ & $(0.001)$ & $1.077^{* * *}$ & $(0.005)$ & $0.007^{* * *}$ & $(0.002)$ & 0.079 & 16435 \\
\hline Equation (IV) & $0.004^{* *}$ & $(0.002)$ & $1.061^{* * *}$ & $(0.006)$ & 0.001 & $(0.002)$ & 0.072 & 16435 \\
\hline $\begin{array}{l}\text { Subsample }(\mathrm{A}) \\
2004 / 07 \text { to } 2007 / 12\end{array}$ & $c$ & & $f$ & & o & & $\begin{array}{c}\text { Standard Error } \\
\text { of Regression }\end{array}$ & Observations \\
\hline Equation (I) & $0.359^{* * *}$ & $(0.016)$ & & & $0.498^{* * *}$ & $(0.032)$ & 0.332 & 6364 \\
\hline Equation (II) & $0.374^{* * *}$ & $(0.017)$ & & & $0.466^{* * *}$ & $(0.039)$ & 0.270 & 6364 \\
\hline Equation (III) & $0.005^{*}$ & $(0.003)$ & $1.078^{* * *}$ & $(0.006)$ & $0.031^{* * *}$ & $(0.007)$ & 0.094 & 6364 \\
\hline Equation (IV) & $0.016^{* * *}$ & $(0.004)$ & $1.067^{* * *}$ & $(0.008)$ & $0.019^{* * *}$ & $(0.007)$ & 0.085 & 6364 \\
\hline $\begin{array}{l}\text { Subsample (B) } \\
2008 / 01 \text { to } 2011 / 02\end{array}$ & $c$ & & $f$ & & $c$ & & $\begin{array}{c}\text { Standard Error } \\
\text { of Regression }\end{array}$ & Observations \\
\hline Equation (I) & $0.369^{* * *}$ & $(0.005)$ & & & $0.217^{* * *}$ & $(0.005)$ & 0.170 & 5535 \\
\hline Equation (II) & $0.369^{* * *}$ & $(0.000)$ & & & $0.209^{* * *}$ & $(0.006)$ & 0.145 & 5535 \\
\hline Equation (III) & $0.030^{* * *}$ & $(0.004)$ & $0.935^{* * *}$ & $(0.011)$ & $0.023^{* * *}$ & $(0.003)$ & 0.078 & 5535 \\
\hline Equation (IV) & $0.033^{* * *}$ & $(0.004)$ & $0.929 * * *$ & $(0.012)$ & $0.018^{* * *}$ & $(0.003)$ & 0.070 & 5535 \\
\hline $\begin{array}{l}\text { Subsample (C) } \\
2011 / 03 \text { to } 2012 / 10\end{array}$ & $c$ & & $f$ & & o & & $\begin{array}{c}\text { Standard Error } \\
\text { of Regression }\end{array}$ & Observations \\
\hline Equation (I) & $0.141^{* * *}$ & $(0.002)$ & & & 0.006 & $(0.005)$ & 0.045 & 2897 \\
\hline Equation (II) & $0.141^{* * *}$ & $(0.001)$ & & & 0.007 & $(0.005)$ & 0.040 & 2897 \\
\hline Equation (III) & -0.001 & $(0.003)$ & $1.047^{* * *}$ & $(0.021)$ & 0.003 & $(0.004)$ & 0.027 & 2897 \\
\hline Equation (IV) & -0.002 & $(0.003)$ & $1.052^{* * *}$ & $(0.022)$ & $0.004^{*}$ & $(0.002)$ & 0.022 & 2897 \\
\hline $\begin{array}{l}\text { Subsample (D) } \\
2012 / 11 \text { to } 2013 / 10\end{array}$ & $c$ & & $f$ & & o & & $\begin{array}{c}\text { Standard Error } \\
\text { of Regression }\end{array}$ & Observations \\
\hline Equation (I) & $0.099^{* * *}$ & $(0.003)$ & & & $0.007^{* * *}$ & $(0.003)$ & 0.037 & 1639 \\
\hline Equation (II) & $0.094^{* * *}$ & $(0.002)$ & & & $0.013^{* * *}$ & $(0.002)$ & 0.034 & 1639 \\
\hline Equation (III) & $0.007^{* *}$ & $(0.003)$ & $0.966^{* * *}$ & $(0.029)$ & 0.000 & $(0.002)$ & 0.025 & 1639 \\
\hline Equation (IV) & $0.006^{* *}$ & $(0.003)$ & $0.954^{* * *}$ & $(0.029)$ & $0.002^{*}$ & $(0.001)$ & 0.021 & 1639 \\
\hline
\end{tabular}

Table 2: Regressions of interest rate expectations on inflation expectations at the 2-year horizon. ***,**, and $*$ indicate $1 \%, 5 \%$, and $10 \%$ significance, respectively. White period standard errors for heteroscedasticity and serial correlation are reported in parenthesis. 


\begin{tabular}{|c|c|c|c|c|c|c|c|c|}
\hline $\begin{array}{l}\text { All sample } \\
2004 / 07 \text { to } 2013 / 10\end{array}$ & $c$ & & $\rho$ & & $\alpha$ & & $\begin{array}{c}\text { Standard Error } \\
\text { of Regression }\end{array}$ & Observations \\
\hline Equation (I) & $1.290^{* * *}$ & $(0.015)$ & & & $0.084^{* * *}$ & $(0.013)$ & 0.361 & 16561 \\
\hline Equation (II) & $1.325^{* * *}$ & $(0.012)$ & & & $0.050^{* * *}$ & $(0.012)$ & 0.256 & 16561 \\
\hline Equation (III) & $0.038^{* * *}$ & $(0.009)$ & $1.009^{* * *}$ & $(0.006)$ & $0.016^{* * *}$ & $(0.004)$ & 0.127 & 16561 \\
\hline Equation (IV) & $0.089^{* * *}$ & $(0.012)$ & $0.971^{* * *}$ & $(0.008)$ & $0.014^{* * *}$ & $(0.003)$ & 0.113 & 16561 \\
\hline $\begin{array}{l}\text { Subsample }(\mathrm{A}) \\
2004 / 07 \text { to } 2007 / 12\end{array}$ & $c$ & & $\rho$ & & $\alpha$ & & $\begin{array}{c}\text { Standard Error } \\
\text { of Regression }\end{array}$ & Observations \\
\hline Equation (I) & $1.613^{* * *}$ & $(0.012)$ & & & $0.071^{* * *}$ & $(0.010)$ & 0.209 & 6498 \\
\hline Equation (II) & $1.589^{* * *}$ & $(0.016)$ & & & $0.093^{* * *}$ & $(0.014)$ & 0.184 & 6498 \\
\hline Equation (III) & $0.290^{* * *}$ & $(0.023)$ & $0.864^{* * *}$ & $(0.014)$ & $0.023^{* * *}$ & $(0.007)$ & 0.129 & 6498 \\
\hline Equation (IV) & $0.341^{* * *}$ & $(0.026)$ & $0.832^{* * *}$ & $(0.016)$ & $0.023^{* * *}$ & $(0.007)$ & 0.112 & 6498 \\
\hline $\begin{array}{l}\text { Subsample }(\mathrm{B}) \\
2008 / 01 \text { to } 2011 / 02\end{array}$ & $c$ & & $\rho$ & & $\alpha$ & & $\begin{array}{c}\text { Standard Error } \\
\text { of Regression }\end{array}$ & Observations \\
\hline Equation (I) & $1.280^{* * *}$ & $(0.010)$ & & & $0.079^{* * *}$ & $(0.010)$ & 0.197 & 5545 \\
\hline Equation (II) & $1.261^{* * *}$ & $(0.016)$ & & & $0.098^{* * *}$ & $(0.017)$ & 0.174 & 5545 \\
\hline Equation (III) & $0.189^{* * *}$ & $(0.019)$ & $0.864^{* * *}$ & $(0.015)$ & $0.023^{* * *}$ & $(0.005)$ & 0.130 & 5545 \\
\hline Equation (IV) & $0.196^{* * *}$ & $(0.019)$ & $0.856^{* * *}$ & $(0.015)$ & $0.028^{* * *}$ & $(0.006)$ & 0.114 & 5545 \\
\hline $\begin{array}{l}\text { Subsample (C) } \\
2011 / 03 \text { to } 2012 / 10\end{array}$ & $c$ & & $\rho$ & & $\alpha$ & & $\begin{array}{c}\text { Standard Error } \\
\text { of Regression }\end{array}$ & Observations \\
\hline Equation (I) & $1.036^{* * *}$ & $(0.009)$ & & & $0.018^{* *}$ & $(0.008)$ & 0.168 & 2882 \\
\hline Equation (II) & $1.034^{* * *}$ & $(0.009)$ & & & $0.020^{* *}$ & $(0.010)$ & 0.150 & 2882 \\
\hline Equation (III) & $0.114^{* * *}$ & $(0.018)$ & $0.945^{* * *}$ & $(0.016)$ & 0.008 & $(0.006)$ & 0.098 & 2882 \\
\hline Equation (IV) & $0.119^{* * *}$ & $(0.018)$ & $0.935^{* * *}$ & $(0.017)$ & $0.013^{* * *}$ & $(0.005)$ & 0.083 & 2882 \\
\hline $\begin{array}{l}\text { Subsample (D) } \\
2012 / 11 \text { to } 2013 / 10\end{array}$ & $c$ & & $\rho$ & & $\alpha$ & & $\begin{array}{c}\text { Standard Error } \\
\text { of Regression }\end{array}$ & Observations \\
\hline Equation (I) & $0.760^{* * *}$ & $(0.010)$ & & & 0.003 & $(0.007)$ & 0.143 & 1636 \\
\hline Equation (II) & $0.792^{* * *}$ & $(0.011)$ & & & $-0.026^{* * *}$ & $(0.009)$ & 0.136 & 1636 \\
\hline Equation (III) & -0.003 & $(0.025)$ & $1.052^{* * *}$ & $(0.033)$ & 0.011 & $(0.007)$ & 0.102 & 1636 \\
\hline Equation (IV) & 0.021 & $(0.027)$ & $1.044^{* * *}$ & $(0.035)$ & -0.005 & $(0.005)$ & 0.087 & 1636 \\
\hline
\end{tabular}

Table 3: Regressions of interest rate expectations on inflation expectations at the 10-year horizon. ***,**, and $*$ indicate $1 \%, 5 \%$, and $10 \%$ significance, respectively. White period standard errors for heteroscedasticity and serial correlation are reported in parenthesis. 


\begin{tabular}{|c|c|c|c|c|c|c|c|c|}
\hline $\begin{array}{l}\text { All sample } \\
2004 / 07 \text { to } 2013 / 10\end{array}$ & $c$ & & $f$ & & $\alpha$ & & $\begin{array}{l}\text { Standard Error } \\
\text { of Regression }\end{array}$ & Observations \\
\hline Equation (I) & $0.923^{* * *}$ & $(0.007)$ & & & $0.085^{* * *}$ & $(0.008)$ & 0.237 & 16312 \\
\hline Equation (II) & $0.913^{* * *}$ & $(0.005)$ & & & $0.098^{* * *}$ & $(0.008)$ & 0.189 & 16312 \\
\hline Equation (III) & $0.026^{* * *}$ & $(0.007)$ & $1.013^{* * *}$ & $(0.007)$ & 0.001 & $(0.003)$ & 0.104 & 16312 \\
\hline Equation (IV) & $0.039^{* * *}$ & $(0.008)$ & $0.997^{* * *}$ & $(0.008)$ & 0.002 & $(0.002)$ & 0.095 & 16312 \\
\hline $\begin{array}{l}\text { Subsample (A) } \\
2004 / 07 \text { to } 2007 / 12\end{array}$ & $c$ & & $f$ & & $\alpha$ & & $\begin{array}{l}\text { Standard Error } \\
\text { of Regression }\end{array}$ & Observations \\
\hline Equation (I) & $1.058^{* * *}$ & $(0.013)$ & & & $0.076^{* * *}$ & $(0.017)$ & 0.259 & 6316 \\
\hline Equation (II) & $1.038^{* * *}$ & $(0.009)$ & & & $0.108^{* * *}$ & $(0.015)$ & 0.207 & 6316 \\
\hline Equation (III) & $-0.054^{* * *}$ & $(0.010)$ & $1.084^{* * *}$ & $(0.009)$ & 0.007 & $(0.006)$ & 0.110 & 6316 \\
\hline Equation (IV) & -0.018 & $(0.013)$ & $1.044^{* * *}$ & $(0.012)$ & $0.017^{* * *}$ & $(0.005)$ & 0.102 & 6316 \\
\hline $\begin{array}{l}\text { Subsample (B) } \\
2008 / 01 \text { to } 2011 / 02\end{array}$ & $c$ & & $f$ & & $\alpha$ & & $\begin{array}{l}\text { Standard Error } \\
\text { of Regression }\end{array}$ & Observations \\
\hline Equation (I) & $0.895^{* * *}$ & $(0.008)$ & & & $0.086^{* * *}$ & $(0.008)$ & 0.162 & 5492 \\
\hline Equation (II) & $0.887^{* * *}$ & $(0.010)$ & & & $0.094^{* * *}$ & $(0.011)$ & 0.146 & 5492 \\
\hline Equation (III) & $0.079^{* * *}$ & $(0.012)$ & $0.937^{* * *}$ & $(0.014)$ & 0.006 & $(0.003)$ & 0.103 & 5492 \\
\hline Equation (IV) & $0.110^{* * *}$ & $(0.012)$ & $0.903^{* * *}$ & $(0.014)$ & $0.006^{*}$ & $(0.003)$ & 0.094 & 5492 \\
\hline $\begin{array}{l}\text { Subsample (C) } \\
2011 / 03 \text { to } 2012 / 10\end{array}$ & $c$ & & $f$ & & $\alpha$ & & $\begin{array}{l}\text { Standard Error } \\
\text { of Regression }\end{array}$ & Observations \\
\hline Equation (I) & $0.898^{* * *}$ & $(0.007)$ & & & $0.016^{* *}$ & $(0.007)$ & 0.134 & 2874 \\
\hline Equation (II) & $0.896^{* * *}$ & $(0.006)$ & & & $0.020^{* *}$ & $(0.009)$ & 0.120 & 2874 \\
\hline Equation (III) & $0.133^{* * *}$ & $(0.018)$ & $0.911^{* * *}$ & $(0.020)$ & 0.004 & $(0.005)$ & 0.087 & 2874 \\
\hline Equation (IV) & $0.146^{* * *}$ & $(0.018)$ & $0.895^{* * *}$ & $(0.021)$ & 0.005 & $(0.005)$ & 0.076 & 2874 \\
\hline $\begin{array}{l}\text { Subsample (D) } \\
2012 / 11 \text { to } 2013 / 10\end{array}$ & $c$ & & $f$ & & $\alpha$ & & $\begin{array}{c}\text { Standard Error } \\
\text { of Regression }\end{array}$ & Observations \\
\hline Equation (I) & $0.651^{* * *}$ & $(0.005)$ & & & $0.023^{* * *}$ & $(0.007)$ & 0.129 & 1630 \\
\hline Equation (II) & $0.653^{* * *}$ & $(0.003)$ & & & $0.016^{*}$ & $(0.009)$ & 0.124 & 1630 \\
\hline Equation (III) & -0.021 & $(0.020)$ & $1.097^{* * *}$ & $(0.032)$ & $0.011^{*}$ & $(0.006)$ & 0.092 & 1630 \\
\hline Equation (IV) & -0.014 & $(0.021)$ & $1.092^{* * *}$ & $(0.035)$ & -0.001 & $(0.006)$ & 0.081 & 1630 \\
\hline
\end{tabular}

Table 4: Regressions of interest rate expectations on inflation expectations at the 8-year horizon (from 2-year to 10-year). ***,**, and * indicate 1\%, 5\%, and $10 \%$ significance, respectively. White period standard errors for heteroscedasticity and serial correlation are reported in parenthesis. 


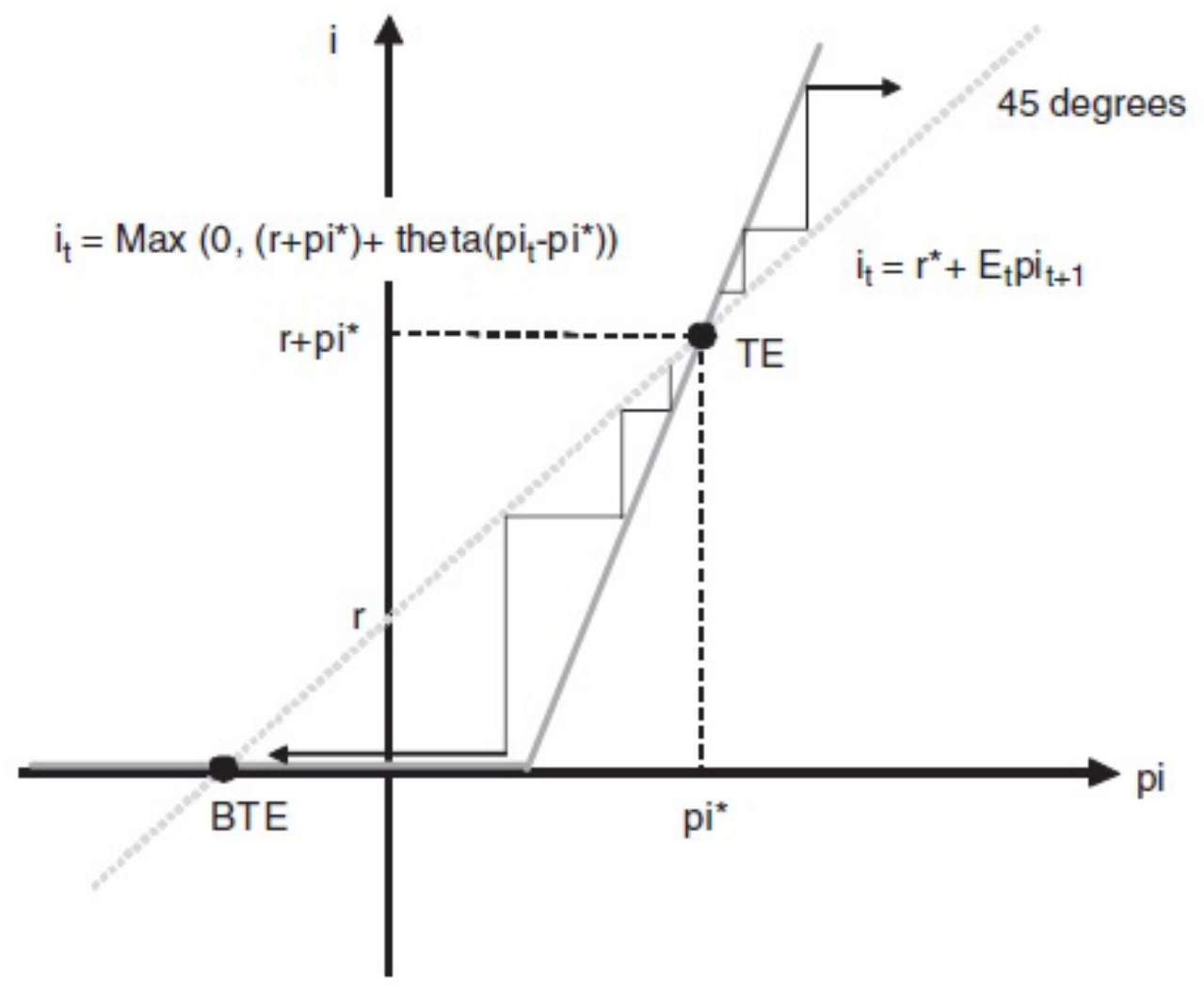

Figure 1: Steady-state multiple equilibrium. 

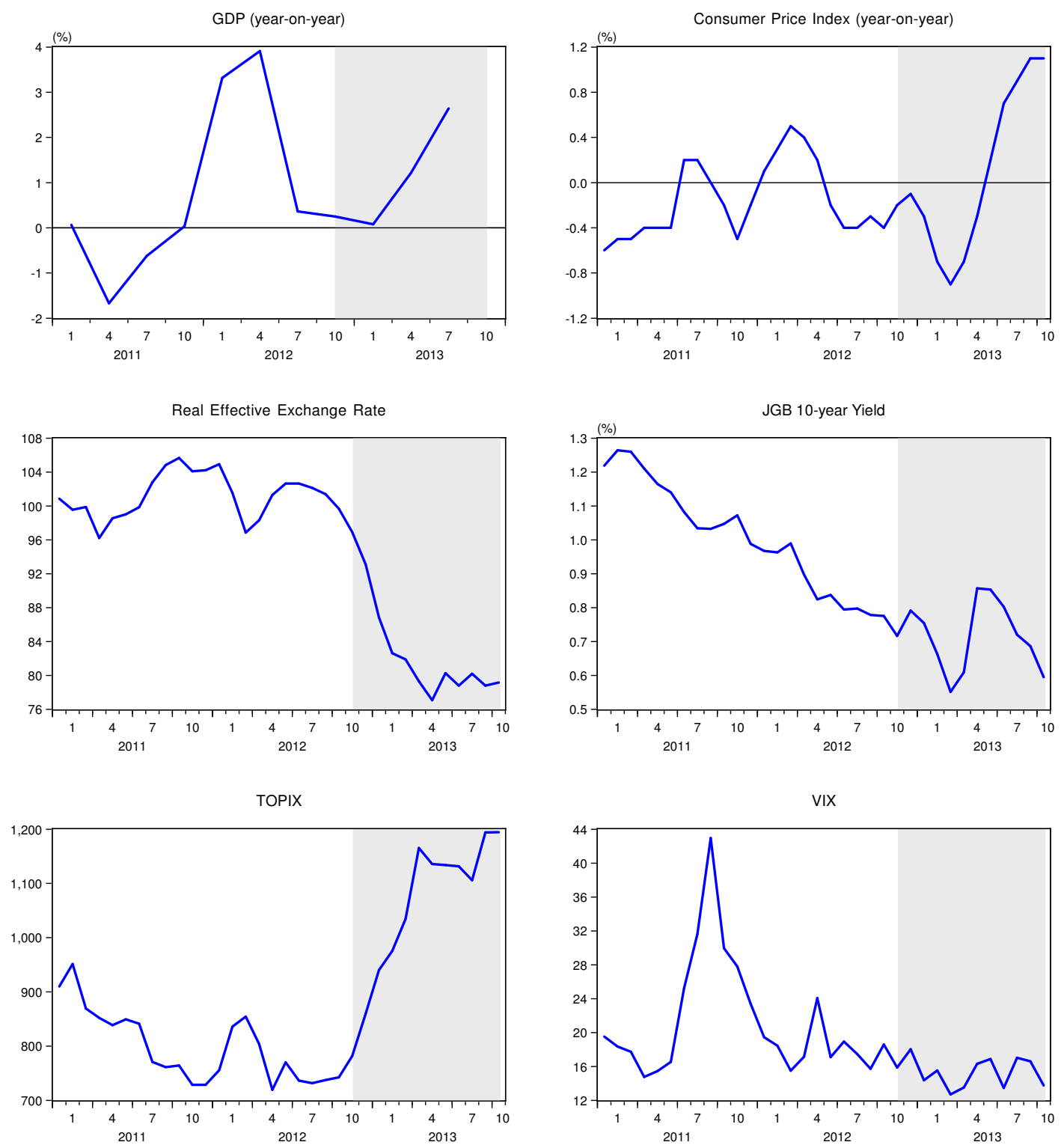

Figure 2: Developments in key economic and financial variables. Shaded area is drawn from November 2012 when Abenomics started. 

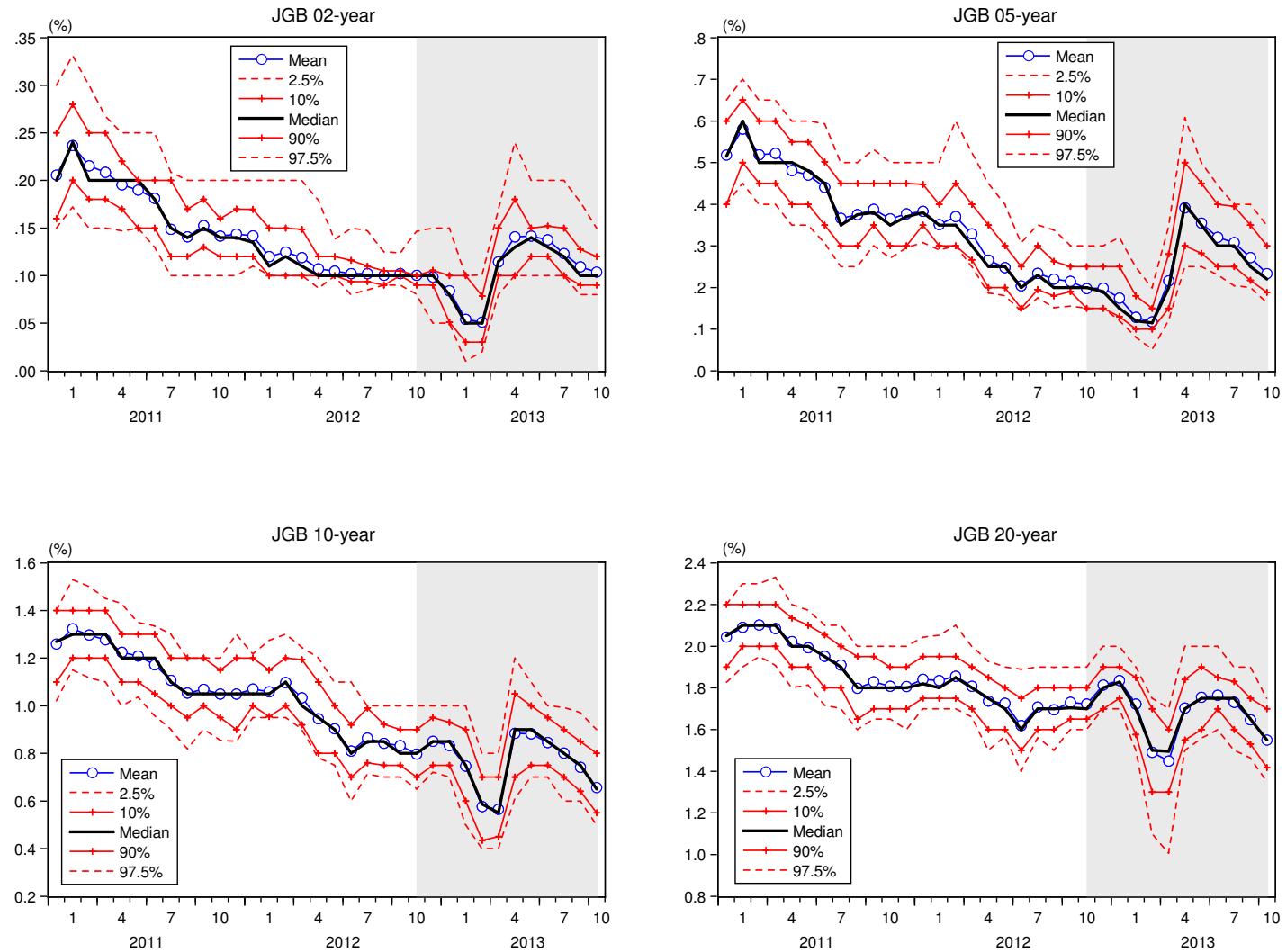

Figure 3: 3-month ahead expectations for 2-, 5-, 10-, and 20-year bond yields. Regarding respondents' expectations in each month, their mean, 2.5th, 10th, 50th (median), 90th and 97.5th percentile points are calculated. Shaded area is drawn from November 2012 when Abenomics started. 


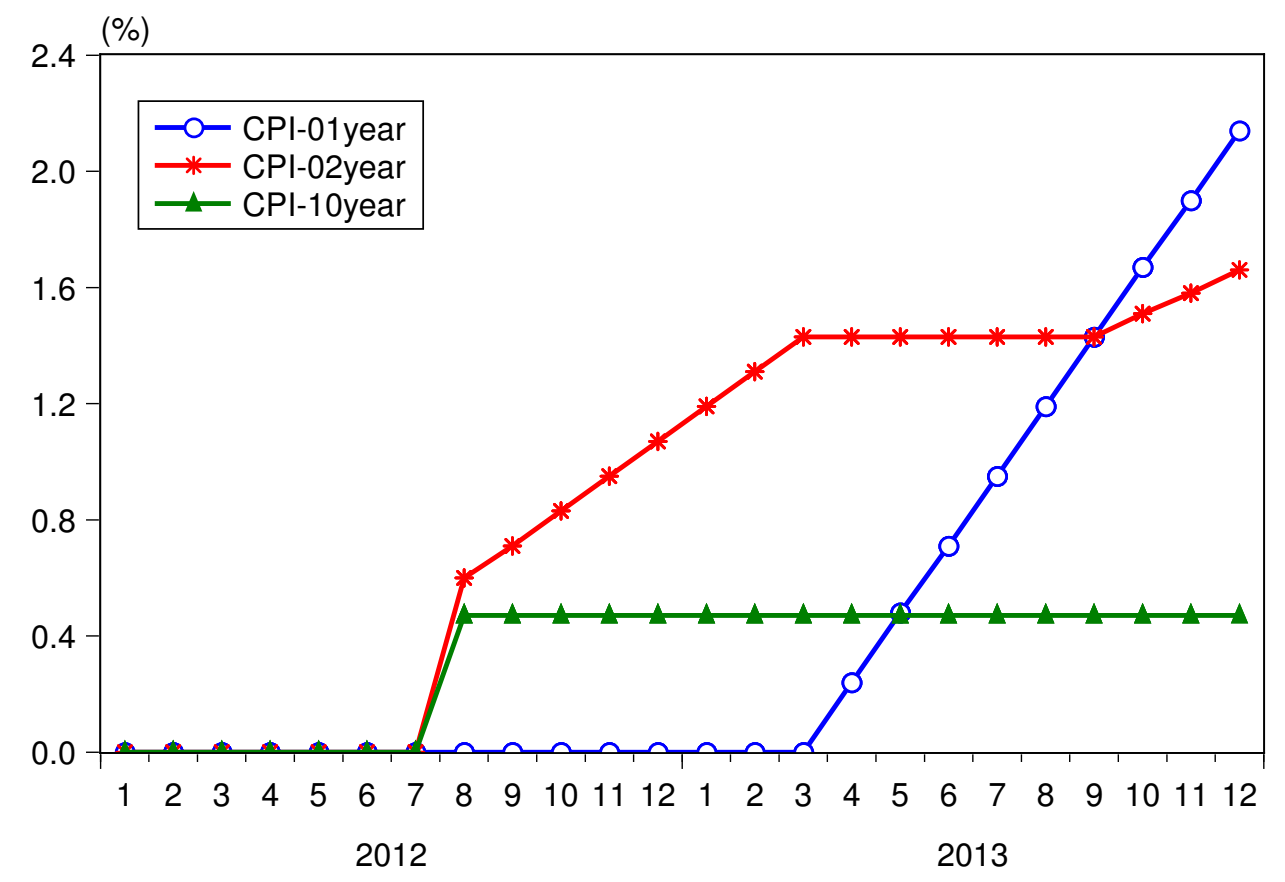

Figure 4: Maximum contribution of consumption-tax rises on inflation expectations. The horizontal axis indicates the month when the survey is conducted. 

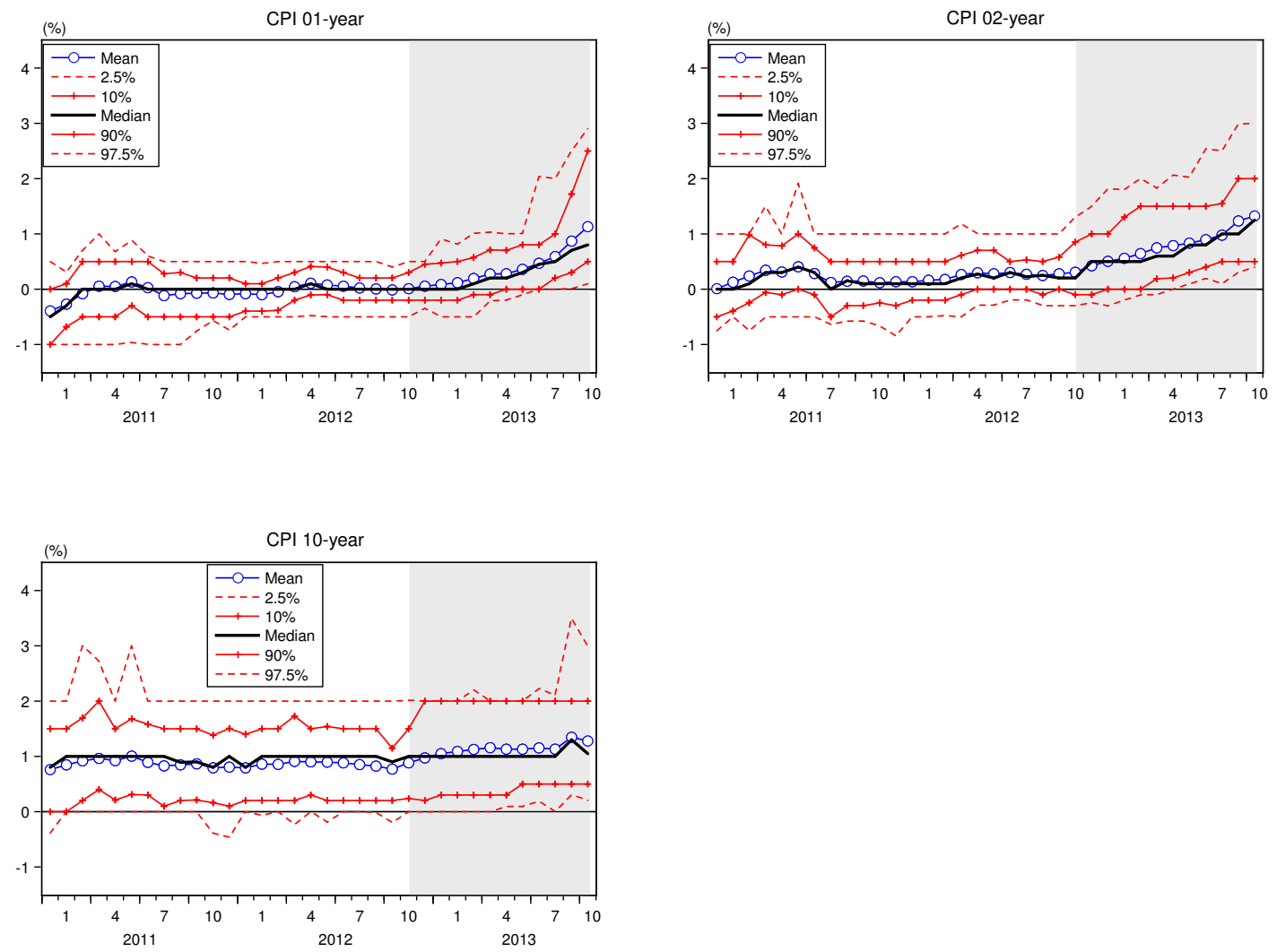

Figure 5: Expectations for the next 1-, 2-, and 10-year inflation rates. Regarding respondents' expectations in each month, their mean, 2.5th, 10th, 50th (median), 90th and 97.5th percentile points are calculated. Shaded area is drawn from November 2012 when Abenomics started. 


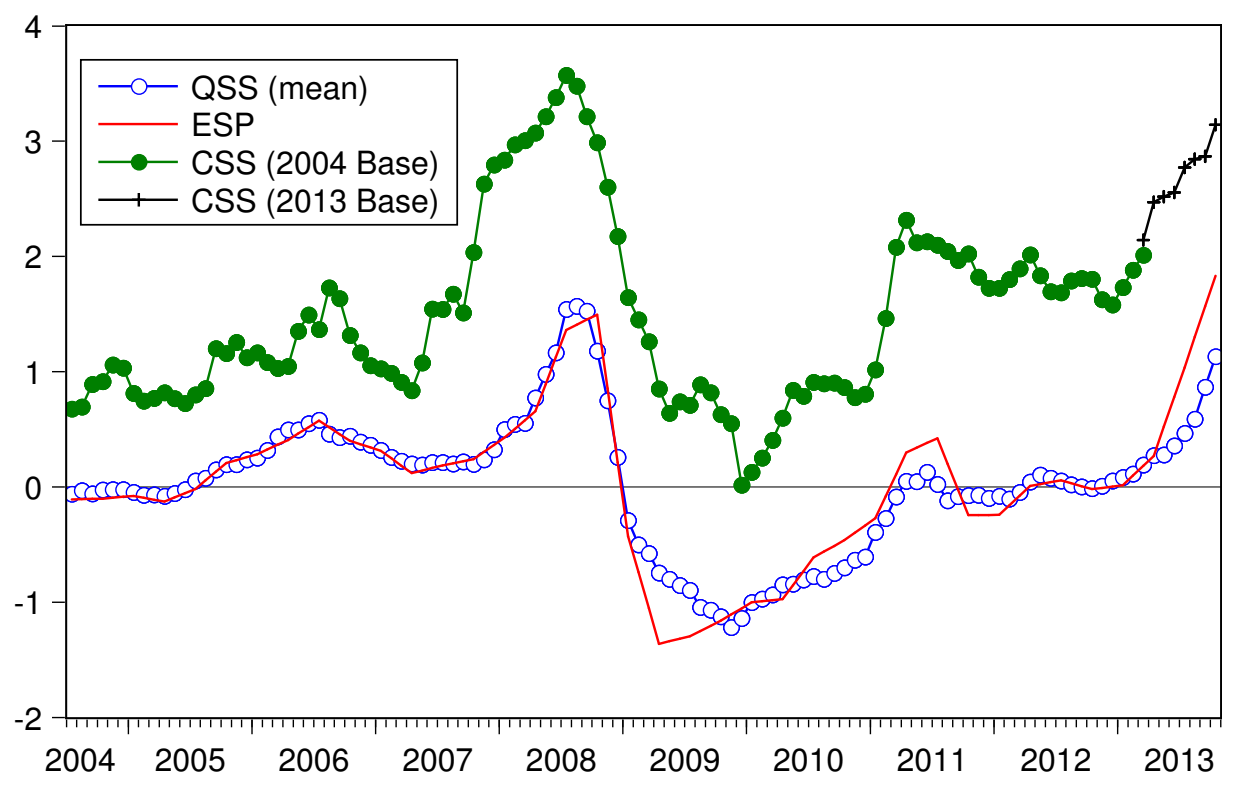

Figure 6: Developments in average inflation expectations over the next 1 year from the QSS, ESP, and CSS. In the CSS, there is discontinuity between figures up to March 2013 because the survey method was changed in April 2013. 

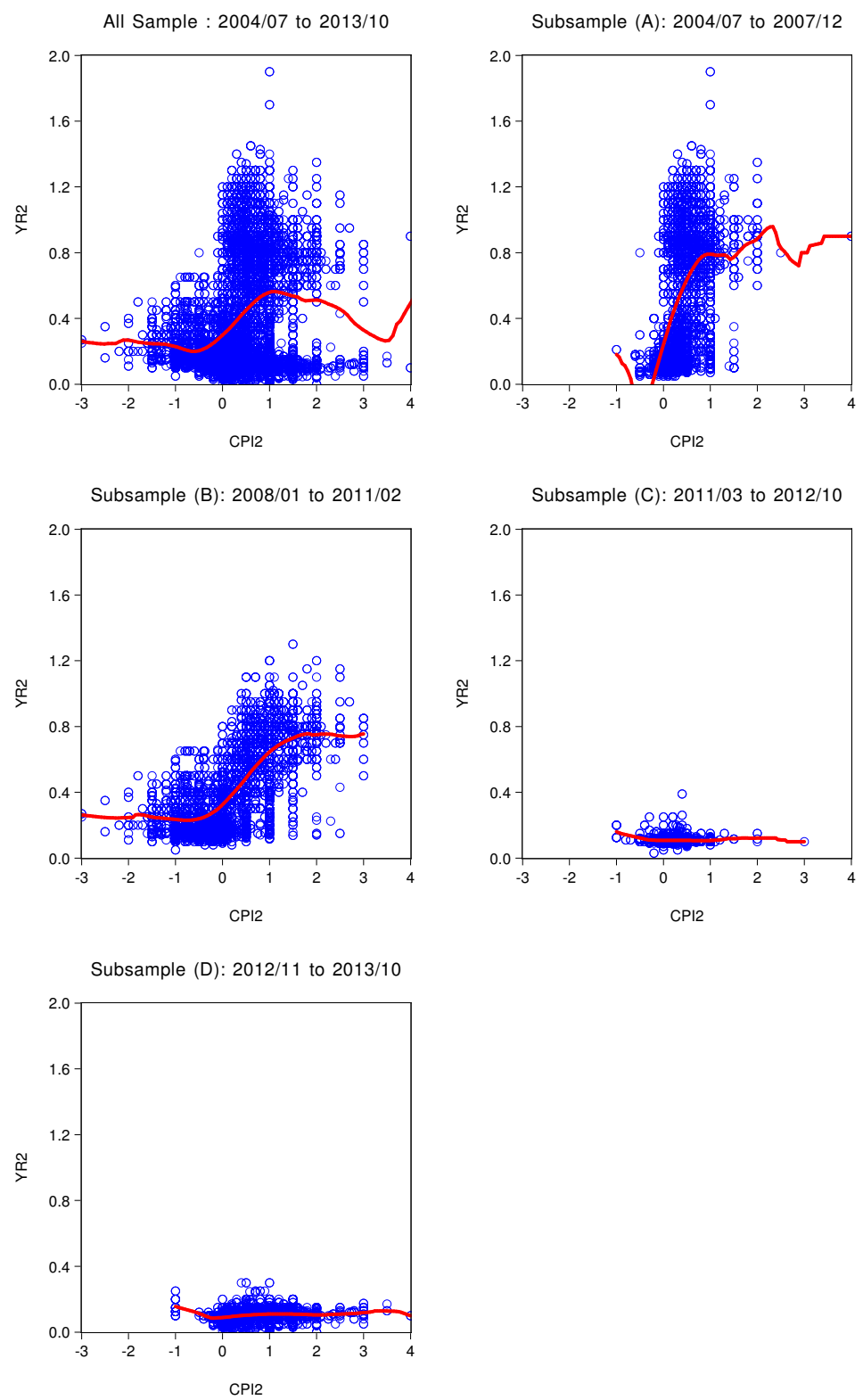

Figure 7: Scattered diagram between inflation expectations over the next 2 years (a horizontal axis) and 3-month ahead expectations for 2-year bond yields (a vertical axis). Each dot plots each respondent's expectations. The top-left panel is those of full samples, while the rest four panels are those of four subsamples (A) to (D). 

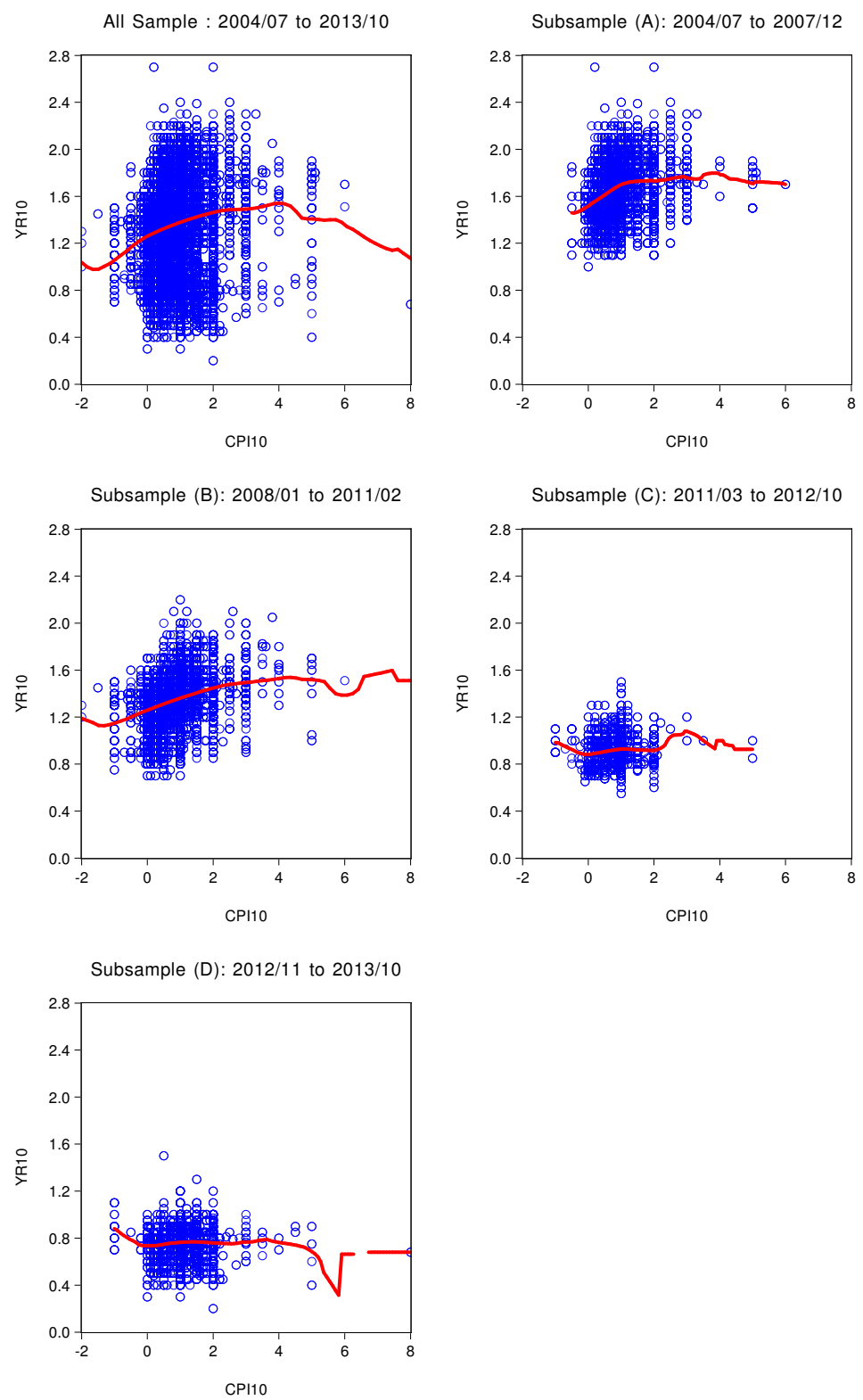

Figure 8: Scattered diagram between inflation expectations over the next 10 years (a horizontal axis) and 3-month ahead expectations for 10-year bond yields (a vertical axis). Each dot plots each respondent's expectations. The top-left panel is those of full samples, while the rest four panels are those of four subsamples (A) to (D). 

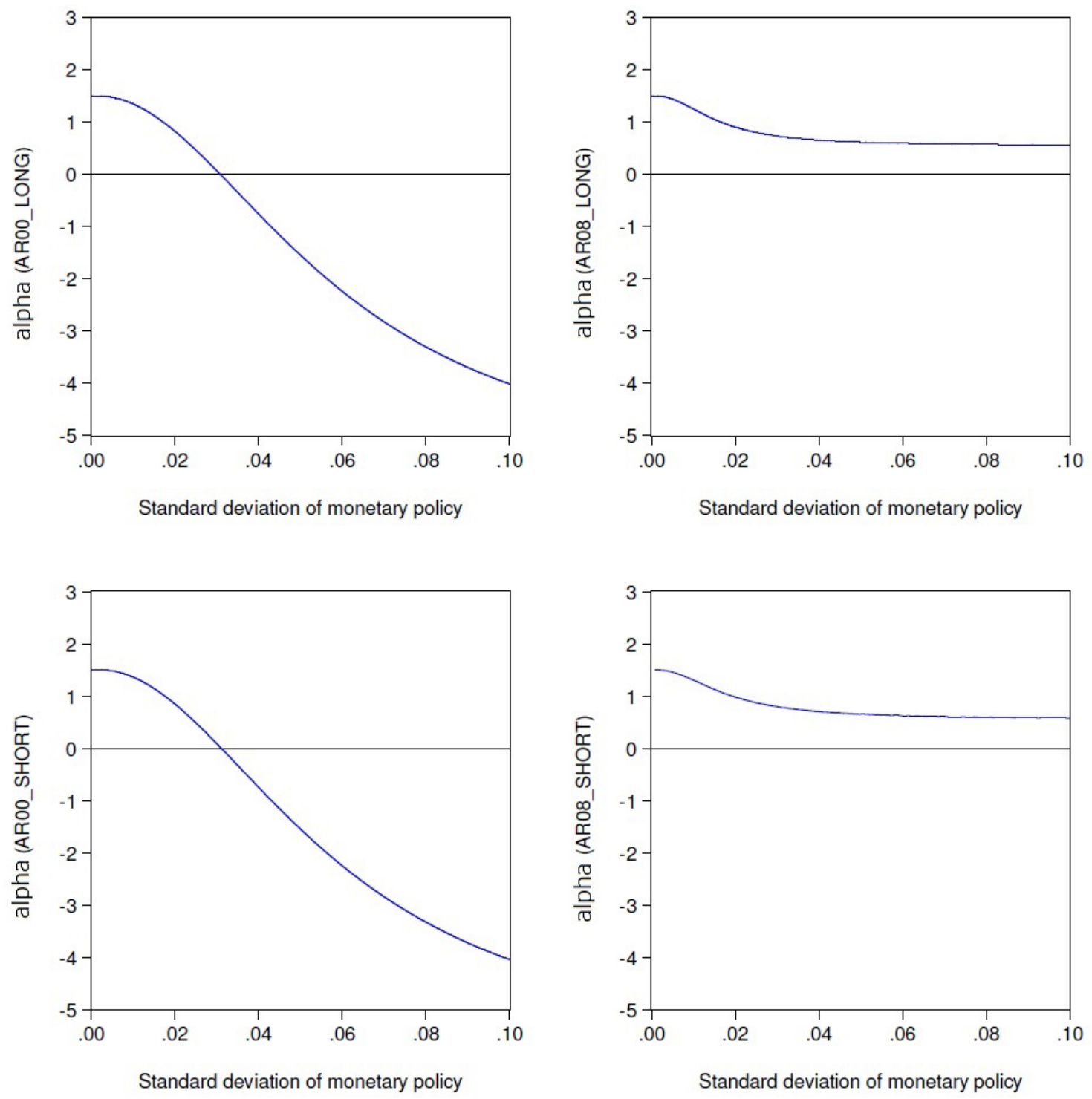

Figure 9: Estimate of $\alpha$ 